\title{
Earth Without Life: A Systems Model of a Global Abiotic Nitrogen Cycle
}

\author{
Matthieu Laneuville, Masafumi Kameya, and H. James Cleaves II 1,2,3,4
}

\begin{abstract}
Nitrogen is the major component of Earth's atmosphere and plays important roles in biochemistry. Biological systems have evolved a variety of mechanisms for fixing and recycling environmental nitrogen sources, which links them tightly with terrestrial nitrogen reservoirs. However, prior to the emergence of biology, all nitrogen cycling was abiological, and this cycling may have set the stage for the origin of life. It is of interest to understand how nitrogen cycling would proceed on terrestrial planets with comparable geodynamic activity to Earth, but on which life does not arise. We constructed a kinetic mass-flux model of nitrogen cycling in its various major chemical forms (e.g., $\mathrm{N}_{2}$, reduced $\left(\mathrm{NH}_{x}\right)$ and oxidized $\left(\mathrm{NO}_{x}\right)$ species) between major planetary reservoirs (the atmosphere, oceans, crust, and mantle) and included inputs from space. The total amount of nitrogen species that can be accommodated in each reservoir, and the ways in which fluxes and reservoir sizes may have changed over time in the absence of biology, are explored. Given a partition of volcanism between arc and hotspot types similar to the modern ones, our global nitrogen cycling model predicts a significant increase in oceanic nitrogen content over time, mostly as $\mathrm{NH}_{x}$, while atmospheric $\mathrm{N}_{2}$ content could be lower than today. The transport timescales between reservoirs are fast compared to the evolution of the environment; thus atmospheric composition is tightly linked to surface and interior processes. Key Words: Nitrogen cycle-Abiotic_Planetology-Astrobiology. Astrobiology 18, 897-914.
\end{abstract}

\section{Introduction}

A TMOSPHERES ARE THE KEY observables that can be obtained remotely of planetary bodies within our solar system, as well as those orbiting other stars. While biosignatures are often studied to potentially detect biotic activity, relatively less research has explored how "geo"-signatures can improve our understanding of planets. In our solar system, for instance, Venus, Earth, and Mars have very different atmospheric nitrogen content, which may inform us about their history. In this contribution, we construct a planetary evolution model to track nitrogen distribution among major planetary reservoirs as mediated by abiotic processes known to occur on Earth. One goal of this study is to help understand what nitrogen content in planetary atmospheres can tell us about its evolution.

Nitrogen (also referred to as $\mathrm{N}$ for the sake of accounting for the mass of nitrogen atoms), in the form of $\mathrm{N}_{2}$ (or molecular nitrogen), is the major component of the present atmosphere and plays important roles in biochemistry (Thomazo and Papineau, 2013). Molecular nitrogen species in biological metabolism are transformed by anabolism, which endergonically synthesizes nitrogenous building blocks, and catabolism, which produces energy by converting high-energy molecules (i.e., 19 $\left.\mathrm{NH}_{x}, \mathrm{NO}_{x}\right)$ into low-energy ones $\left(\mathrm{N}_{2}\right)$. Today, bioavailable nitrogen (i.e., all molecular forms except $\mathrm{N}_{2}$ ), together with iron and phosphorous, is often a growth-limiting nutrient in the environment (Smith, 1984; Vitousek and Howarth, 1991).

The timing of the origin of life is not well constrained, with some authors estimating that Earth may have become habitable by $4.4 \mathrm{Ga}$ (Wilde et al., 2001), there being some evidence of biology before $4 \mathrm{Ga}$ (Dodd et al., 2017) and stronger evidence for biology between $\sim 3.8$ and $3.5 \mathrm{Ga}$, which remains actively debated (e.g., Mojzsis et al., 1996; Noffke et al., 2013). Though there is some evidence that biological $\mathrm{N}_{2}$ fixation may have developed as early as $3.2 \mathrm{Ga}$ (Stüeken et al., 2015) and biological nitrogen utilization

\footnotetext{
${ }^{1}$ Earth-Life Science Institute, Tokyo Institute of Technology, Tokyo, Japan.

${ }^{2}$ The Institute for Advanced Study, Princeton, New Jersey, USA.

${ }^{3}$ Blue Marble Space Institute of Science, Washington, DC, USA.

${ }^{4}$ Center for Chemical Evolution, Georgia Institute of Technology, Atlanta, Georgia, USA.
}

(C) Matthieu Laneuville et al., 2018; Published by Mary Ann Liebert, Inc. This Open Access article is distributed under the terms of the Creative Commons License (http://creativecommons.org/licenses/by/4.0), which permits unrestricted use, distribution, and reproduction in any medium, provided the original work is properly credited. 
Table 1. Estimates for the Sizes of EARTh's NitRogen ReSERVOIRS

\begin{tabular}{lcc}
\hline Reservoir & Mass $N$ & Major species \\
\hline Atmosphere & $4.0 \times 10^{18} \mathrm{~kg}$ & $\mathrm{~N}_{2}$ \\
Biomass & $1.0 \times 10^{15} \mathrm{~kg}$ & $\mathrm{NH}_{x}$ \\
Oceans dissolved & $2.4 \times 10^{16} \mathrm{~kg}$ & $\mathrm{~N}_{2}$ \\
Sedimentary rocks & $2 \times 10^{17} \mathrm{~kg}$ & $\mathrm{NH}_{x}$ \\
Continental crust & $1.7 \times 10^{18} \mathrm{~kg}$ & $\mathrm{NH}_{x}$ \\
Mantle & $2.8 \times 10^{19} \mathrm{~kg}$ & $\mathrm{NH}_{x}$ \\
Core & $1.7 \times 10^{20} \mathrm{~kg}$ & $\mathrm{Fe}_{x} \mathrm{~N}_{y}$ \\
\hline
\end{tabular}

Values are cited from the work of Johnson and Goldblatt (2015).

may have been active by $3.8 \mathrm{Ga}$ (Papineau et al., 2005), this still leaves potentially $0.5-1$ billion years during which biology could have existed on Earth but had little effect on the drawdown of nitrogen from the atmosphere. Earth is sometimes assumed to have a chondritic composition ( $\mathrm{McD}$ Donough and Sun, 1995; Javoy et al., 2010), although there are differing opinions (Campbell and O'Neill, 2012). Assuming either a carbonaceous or enstatite chondrite composition gives a range of values for the bulk terrestrial nitrogen inventory of 2.0 $3.3 \times 10^{20} \mathrm{~kg}$ (Johnson and Goldblatt, 2015). After the core (the $\mathrm{N}$ content of which is unknown), the major reservoirs are the atmosphere, the crust, sediments, and the mantle with on the order of $10^{18} \mathrm{~kg}$ in each reservoir, while the oceans only hold about $10^{16} \mathrm{~kg}$ (Table 1). The oceans, however, serve as a major conduit between the atmosphere and Earth's interior and therefore play an important role in the global nitrogen cycle. Similarly, biomass is a small reservoir (about $10^{15} \mathrm{~kg}$ ), but the nitrogen flux through it is large. Although the core is potentially the largest nitrogen reservoir, it is ignored in this model: even if the extent of core-mantle interactions is debated, nitrogen fluxes between these two reservoirs are likely small (Hayden and Watson, 2007). More details about the constraints for the nitrogen content of each reservoir can be found in Appendix A.

The way nitrogen cycles between reservoirs on terrestrial planets is contingent on a number of variables. For example, Venus, though slightly smaller than Earth, may have accreted from similar bodies to those that formed Earth and thus initially have had a proportionately similar amount of nitrogen (Wordsworth, 2016) (see Table 2). Although the

Table 2. Measured and Estimated Abundances OF Nitrogen IN THE ATMOSPHERES AND INTERIORS OF VENUS, EARTH, AND MARS

\begin{tabular}{lccc}
\hline & Venus & Earth & Mars \\
\hline Total surf. pressure (bar) & 92 & 1 & 0.01 \\
Atmospheric mass (kg) & $4.8 \times 10^{20}$ & $5.2 \times 10^{18}$ & $2.5 \times 10^{16}$ \\
Atmospheric N mass (kg) & $1.7 \times 10^{19}$ & $4.0 \times 10^{18}$ & $4.7 \times 10^{14}$ \\
Atmospheric N fraction & 0.035 & 0.78 & 0.0189 \\
Mass planet & $4.9 \times 10^{24}$ & $6.0 \times 10^{24}$ & $6.4 \times 10^{23}$ \\
Est. bulk silicate N (kg) & $2.2 \times 10^{19}$ & $3.4 \times 10^{19}$ & $2.9 \times 10^{18}$ \\
N atm./bulk silicate N & 0.76 & 0.12 & $1.63 \times 10^{-4}$ \\
\hline
\end{tabular}

Data from http://nssdc.gsfc.nasa.gov/planetary/factsheet and Johnson and Goldblatt (2015). The bulk silicate $\mathrm{N}$ values were estimated by scaling Earth's value to Venus' and Mars' masses. proportion of nitrogen in Venus' atmosphere is smaller in terms of mass percent (3.5\% vs. $78 \%$ ), its total atmospheric $\mathrm{N}$ content is roughly 4 times that of Earth, further suggesting a large fraction of Earth's $\mathrm{N}$ is contained in deep reservoirs that have not outgassed or are replenished by subduction to a degree not possible on Venus (Wordsworth, 2016). The $\mathrm{N}$ content of Venus' atmosphere is roughly commensurate with an entire original chondritic inventory being present in its atmosphere.

Likewise, Mars, though it has a tenuous atmosphere (mostly due to its small mass and lack of a geodynamo, which may have allowed widespread volatile loss over its history [Bogard et al., 2001]), has a significant atmospheric nitrogen component ( $\sim 2$ wt \%, Mahaffy et al., 2013). While deep martian nitrogen reservoirs remain almost wholly unknown (e.g., Mohapatra and Murty, 2003), it has been estimated that Mars has lost $99 \%$ of its original atmospheric content (McElroy et al., 1977; Hutchins and Jakosky, 1996). Beyond the $\mathrm{N}_{2}$ and $\mathrm{NO}_{x}$ species present in its atmosphere, nitrates have now been detected on the surface (Stern et al., 2015) and in martian meteorites (Kounaves et al., 2014), suggesting there are some geochemical processes common to Earth and Mars such as fixation by meteorite impacts or lightning.

The evolutionary dynamics of Venus and Mars are not explored in this study, but we note that, once the influence of key processes on nitrogen distribution is identified, the different fates of nitrogen on the three bodies can be used to set constraints on their relative evolution.

The evolution of terrestrial nitrogen cycling has been studied previously, with different goals than those explored here. Mancinelli and McKay (1988) used constraints on abiotic fixation mechanisms to discuss the evolutionary sequence of biological nitrogen metabolism. In particular, they provided improved lightning and shock-induced fixation rates to argue that nitrogen fixation evolved later than denitrification, due to the relative availability of fixed nitrogen in Earth's early environment.

Later, Zhang and Zindler (1993) presented a global cycling model using new constraints on mantle degassing rates from $\mathrm{CO}_{2} / \mathrm{He}$ and $\mathrm{N}_{2} / \mathrm{Ar}$ ratios at mid-ocean ridges. They used a 2box model to track the amount of "degassable" carbon and nitrogen as a function of time and therefore neglected any flux buffering associated with nitrogen fixation. They found an almost constant atmospheric $\mathrm{N}_{2}$ pressure after an initial transient stage of several $100 \mathrm{Ma}$, and that long-term variation in recycling efficiency would not produce observable effects on atmospheric measurements because of the timescales involved.

More recently, Stüeken et al. (2016) developed an updated evolutionary model focusing on atmospheric nitrogen content to test whether abiotic processes could be the cause of the potentially large fluctuations in $\mathrm{pN}_{2}$ observed (Marty et al., 2013; Som et al., 2016). They constructed a box model with imposed global variations (such as global oxygenation events, global crustal melting) and tested how they propagate through the system. Long-term variation in atmospheric nitrogen content was found to be below observable levels, suggesting a biotic origin for the large fluctuations in $\mathrm{pN}_{2}$.

In our model, we consider speciation of nitrogen $\left(\mathrm{N}_{2}\right.$, reduced and oxidized) and further keep the ocean as a separate reservoir, specifically the only reservoir where the different nitrogen species can coexist in significant amounts. 
As different redox state nitrogen species react differently in the environment (e.g., only reduced nitrogen is efficiently adsorbed onto sediments), bottlenecks may be created in the system. In particular, we would like to understand how environmental variables affect global circulation of nitrogen.

In the next section, we present our geodynamical model and describe how the different nitrogen fluxes can be parameterized. We then present the predictions that can be made for an "Earth-like" body (meaning a body where the geodynamics and initial nitrogen budget are similar to those of Earth). We finally discuss which parts of this model most influence the ultimate planetary distribution of $\mathrm{N}$ and what inferences can be made regarding other bodies in our solar system and beyond.

\section{Methods}

Our basic model considers coupling between various reservoirs, where the mass of any species in a reservoir is a balance of the mass flux into the reservoir minus the flux out of the reservoir due to mass transfer and chemical reactions. We also consider speciation within reservoirs with respect to the redox state of nitrogen. Figure 1 presents a simplified model topology. In the following subsections, the detailed contributions of each flux are outlined.

The major nonbiological mechanisms that govern the flux of nitrogen on planetary scales are atmospheric fixation by impacts and lightning, rainout, aqueous phase chemistry, adsorption to mineral phases, subduction, and remineralization. The model presented here includes terms for reversible

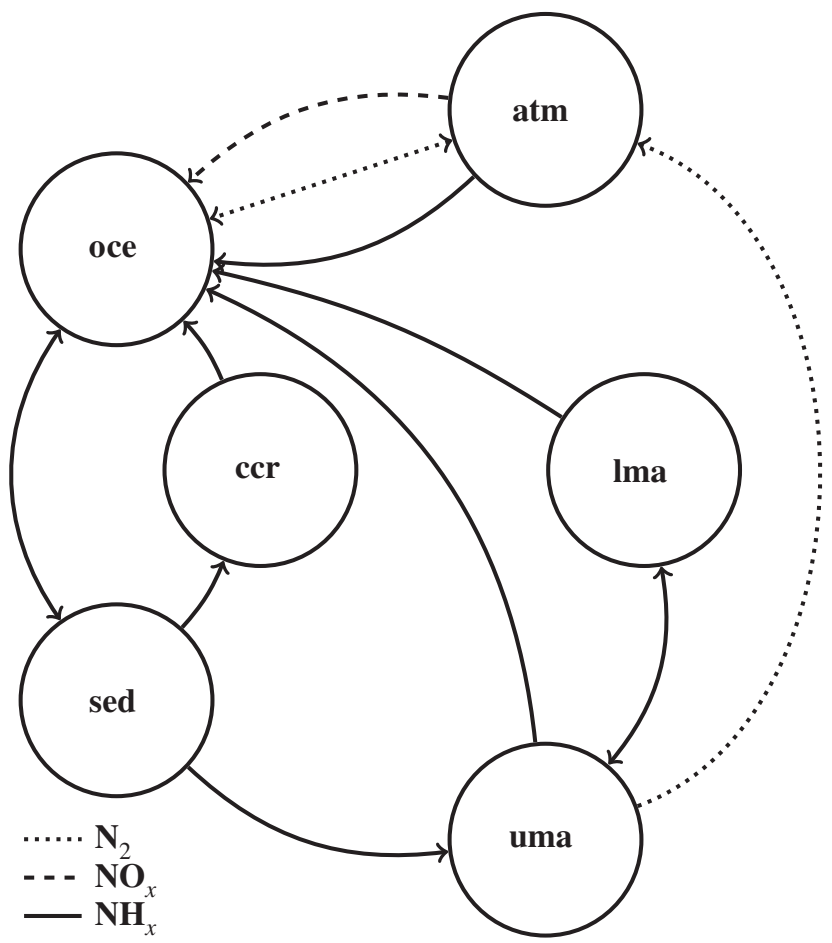

FIG. 1. Model topology used in this study. Circles represent nitrogen reservoirs and correspond, clockwise, to atmosphere (atm), lower (lma) and upper (uma) mantle, marine sediments (sed), continental crust (ccr), and oceans (oce). Arrows represent fluxes between reservoirs, with arrow style indicating the nitrogen speciation of that flux. transport between the atmosphere and oceans, reactions in the aqueous phase, transformation in hydrothermal settings, reversible adsorption to mineral phases (e.g., marine sediments), subduction of marine sediments, accretion of continental crust and erosion, transformation and outgassing during subduction, and release of mantle nitrogen via hotspot volcanism.

The continental crust volume as a function of time can be estimated from variation in the isotopic composition of zircons. Dhuime et al. (2012) identified a transition between an early rapid growth of the continents at about $3 \mathrm{~km}^{3} \mathrm{yr}^{-1}$ until $\sim 3 \mathrm{Ga}$, followed by a longer, slower growth period at $0.8 \mathrm{~km}^{3} \mathrm{yr}^{-1}$ from then until the present day. They speculate that this transition may be due to the onset of subduction, which reduced the effective amount of crust accreted onto continents. As such scenarios are still debated, we also tested a constant growth rate model (e.g., Belousova et al., 2010).

The values used in this model were compiled from careful consideration of likely sources and sinks of $\mathrm{N}$ species according to presently measured parameters and fluxes, but the error in these nitrogen mass flux estimates may be large (see the following subsections for more details). Below, we present the rationale for our choices. The variability of our conclusions and their dependence on uncertainties in the model parameters are discussed in the following section.

\subsection{Extraterrestrial input}

Contributions from space are modeled as coming from two possible sources. The first is net input of reduced nitrogen from comets, asteroids, meteorites, and interstellar dust particles as described by Chyba and Sagan (1992). These calculations are based on cometary studies and the lunar cratering record, which have been used to determine the carbon fluxes from these sources. We used a N/C ratio in comets of 0.1 (Mumma and Charnley, 2011) to obtain a net nitrogen flux. However, Marty et al. (2016) suggested that cometary volatiles may have made a minor contribution to Earth's budget, so this should be considered a generous estimate. Even so, it can be seen that this contributes a relatively small amount of nitrogen to the modeled system (see Fig. 2a).

The second extraterrestrial contribution comes from impacts, which also likely served as an energy source to fix atmospheric $\mathrm{N}_{2}$ to soluble species. For impact shocks, the amount of endogenous carbon that gets fixed as a function of time has been computed (Chyba and Sagan, 1992). We assume here that nitrogen is fixed at the same rate as carbon. Depending on the redox state of the atmosphere, nitrogen abiotically fixed that way can be in the form of either reduced or oxidized compounds. In both cases, rainout time is considered to be negligible compared to geological timescales, and nitrogen was added as dissolved species to the ocean reservoir directly. The time dependence of this flux was parameterized as

$$
F(t)=F_{0}+\left(F_{1}-F_{0}\right) \exp ^{-t / \tau}
$$

where $\tau$ is $150 \mathrm{Ma}$ and $F_{0}$ and $F_{1}$ are $2.4 \times 10^{5}$ and $2.4 \times 10^{8} \mathrm{~kg} \mathrm{~N} \mathrm{yr}^{-1}$ for the cometary input and $4.7 \times 10^{6}$ and $4.7 \times 10^{9} \mathrm{~kg} \mathrm{~N} \mathrm{yr}^{-1}$ for impact fixation, respectively. For impact fixation, the flux was linearly scaled to the present-day atmospheric nitrogen content of $4 \times 10^{18} \mathrm{~kg}$ (i.e., $F$ is divided 

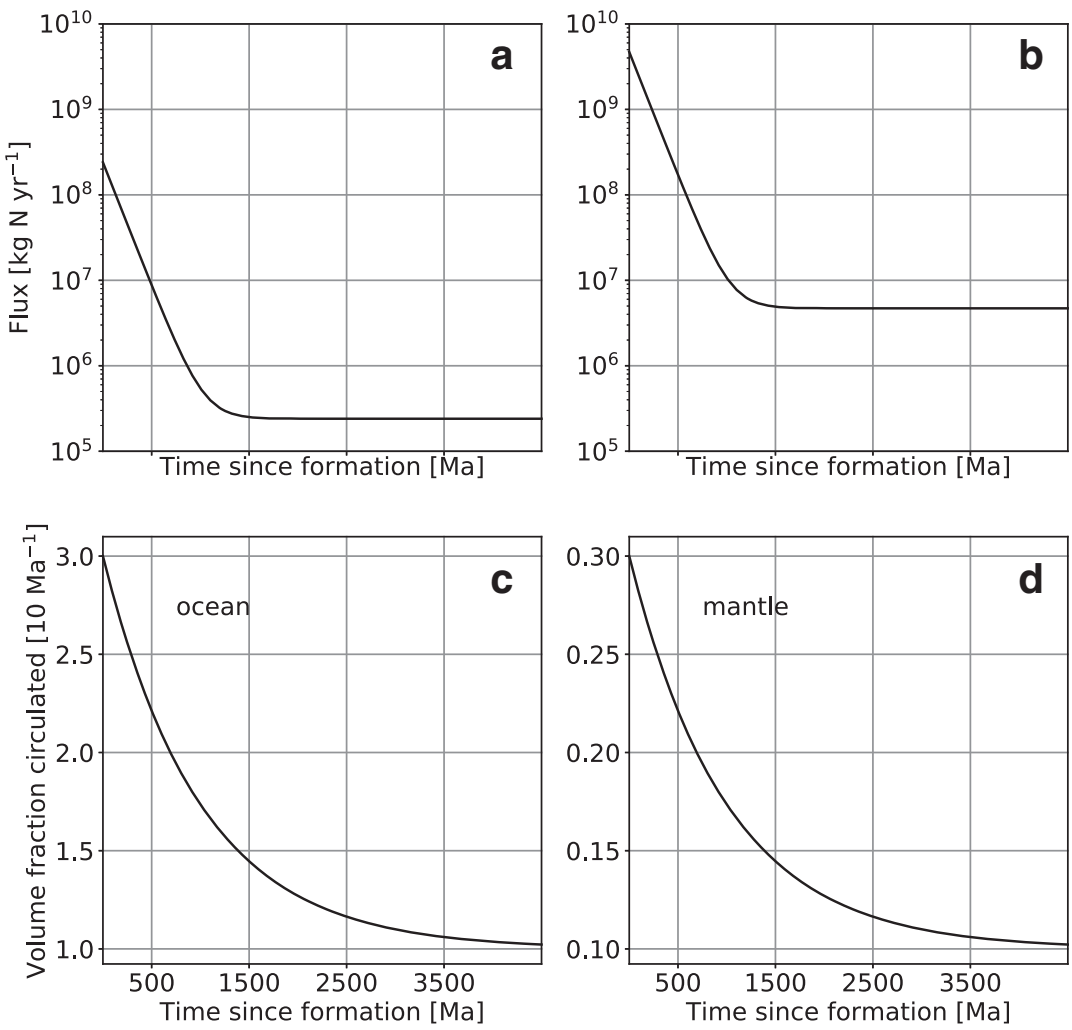

FIG. 2. Model time dependence of the fluxes. (a) Net nitrogen addition to the Earth system from extraterrestrial sources. (b) Atmospheric $\mathrm{N}_{2}$ fixation by impacts. This flux is scaled to 1 PAL $\mathrm{N}_{2}$. (c) Ocean volume fraction circulated through hydrothermal vents per $10 \mathrm{Ma}$. (d) Mantle fraction circulated per $10 \mathrm{Ma}$. This constrains the rate at which the upper and lower mantle equilibrate. The last two functions act as a prefactor to the overall mass flux calculation. by two if $\mathrm{pN}_{2}$ is 0.5 PAL). Figures $2 \mathrm{a}$ and $2 \mathrm{~b}$ show the fixation time dependence for these fluxes. Note that impact statistics in the work of Chyba and Sagan (1992) is consistent with the concept of Late Heavy Bombardment but does not consider singular events such as the putative Moonforming giant impact.

\subsection{Atmosphere to surface}

Yung and McElroy (1979) estimated abiotic nitrogen fixation due to atmospheric electric discharges as $1-4 \times 10^{10} \mathrm{~kg} \mathrm{yr}^{-1}$ in an oxidizing atmosphere and $2 \times 10^{9} \mathrm{~kg} \mathrm{yr}^{-1}$ in a reducing one. Borucki and Chameides (1984) gave the present rate of abiological atmospheric fixation as $\sim 2.6 \times 10^{9} \mathrm{~kg} \mathrm{yr}^{-1}$. Navarro-Gonzalez et al. (2001) showed experimentally that this value may be relevant for a $\mathrm{CO}_{2}$-dominated atmosphere, while the fixation rate in an $\mathrm{N}_{2}$-dominated atmosphere could be much lower, around $2.6 \times 10^{6} \mathrm{~kg} \mathrm{yr}^{-1}$. Galloway et al. (2013) also tabulated modern $\mathrm{N}$ fixation rates by lightning as between $3 \times 10^{9}$ and $10 \times 10^{9} \mathrm{~kg} \mathrm{~N} \mathrm{yr}^{-1}$. For consideration, in the absence of remineralization processes (and assuming the rates are pressure-independent), these fixation rates would allow for the complete fixation of the present mass of atmospheric $\mathrm{N}_{2}$ in $\sim 0.1-1 \mathrm{Ga}$.

In general, the residence times of odd nitrogen species in the atmosphere, which include $\mathrm{NH}_{3}, \mathrm{NO}, \mathrm{NO}_{2}, \mathrm{HNO}_{3}, \mathrm{~N}_{2} \mathrm{O}$, $\mathrm{HONO}_{x}$, and $\mathrm{N}$-containing organic compounds, with the exception of $\mathrm{N}_{2} \mathrm{O}$, are only hours to days (Chameides, 1975), which is much smaller than the time step in our model (5000 years). We therefore assume fixed nitrogen species are instantaneously transported to, and dissolved in, the oceans.

To account for abiotic fixation by lightning, we used a constant flux of $\mathrm{N}_{2}$ to $\mathrm{NO}_{x}$ and $\mathrm{NH}_{x}$, linearly scaled to at- mospheric $\mathrm{pN}_{2}$. For an atmospheric mass of $4 \times 10^{18} \mathrm{~kg}$, the fluxes to $\mathrm{NO}_{x}$ and $\mathrm{NH}_{x}$ are $4 \times 10^{10}$ and $1.6 \times 10^{7} \mathrm{~kg} \mathrm{~N} \mathrm{yr}^{-1}$, respectively, for the $\mathrm{CO}_{2}$-dominated case and $2.6 \times 10^{6}$ and $10^{3} \mathrm{~kg} \mathrm{~N} \mathrm{yr}^{-1}$ for the $\mathrm{N}_{2}$-dominated one.

We used Henry's law to determine the equilibrium concentration of $\mathrm{N}_{2}$ in the oceans:

$$
K=\frac{p}{c}
$$

where $K$ is Henry volatility for nitrogen and $p$ is $\mathrm{N}_{2}$ partial pressure in the atmosphere and $c$ its concentration in the ocean. Assuming a modern average circulation time of 1600 years, the oceans are considered here as well mixed at all times. The timescales of soluble species reactivity and adsorption are also short relative to advection and diffusion; thus all species dissolved in the ocean reservoir also equilibrate instantaneously. Assuming a mean ocean temperature of $25^{\circ} \mathrm{C}$, the Henry's law constant for $\mathrm{N}_{2}$ is $1600 \mathrm{~L} \mathrm{~atm} \mathrm{~mol}^{-1}$ (Sander, 2015), though this decreases by a factor of about 4 between $0^{\circ} \mathrm{C}$ and $100^{\circ} \mathrm{C}$, which in turn would decrease the ratio of dissolved $\mathrm{N}_{2}$ to atmospheric $\mathrm{N}_{2}$ by a factor of 4 were the oceans at a mean temperature of $100^{\circ} \mathrm{C}$.

We considered two atmospheric redox states: a generally neutral $\left(\mathrm{N}_{2}\right.$-dominated) atmosphere and one with significant amounts of reduced gases (e.g., $\mathrm{CH}_{4}$ or $\mathrm{CO}$ ), corresponding to a low and high abiotic fixation rate, respectively. Both types are plausibly concordant with the geological record and planetary evolution models (Kasting et al., 1993; Canil, 1997; Delano, 2001; Trail et al., 2011). Though it seems possible that the upper mantle was more reduced during the earliest stages of Earth's differentiation (Arculus and Delano, 1980; Holland, 1984; Frost and McCammon, 2008), this is generally 
before the time period considered here. We also neglect the influence this parameter would have on the abiotic fixation rate, as the effect is not well parameterized.

\subsection{Hydrothermal vent transformations}

Presently, the entire ocean volume cycles through marine hydrothermal systems approximately every 10 million years (Holland, 1984), where a fraction of that volume then reacts within the vent systems. A higher rate of internal heat production on the early Earth would have led to increased volcanic and tectonic activity and a likely concurrent increase in hydrothermal vent activity and ocean circulation rates through them (Turcotte, 1980). We therefore explored system evolution with either constant or exponentially decreasing rates of hydrothermal circulation through time. We use the same functional form as Eq. 1, with $F_{0}=1 \times 10^{-7}$ and $F_{1}=3 \times 10^{-7} \mathrm{yr}^{-1}$, respectively. The resulting evolution can be seen in Fig. 2c.

We assumed that the nitrogen-reduction reactions described by Brandes et al. (1998) (which describes the reduction of nitrite, nitrate, and $\mathrm{N}_{2}$ to $\mathrm{NH}_{3}$ ) and Summers (2005) (which describes the reduction of nitrite and nitrate to $\mathrm{NH}_{3}$ at lower temperatures than those of Brandes et al. [1998]) operate during hydrothermal circulation. Thus, all of the circulated $\mathrm{NO}_{x}$ and $0.1 \%$ of dissolved $\mathrm{N}_{2}$ are converted to $\mathrm{NH}_{x}$ via combined on- and off-axis alteration. The abovecited experiments have shown that nitrate and nitrite are reduced much more efficiently than $\mathrm{N}_{2}$; thus this ratio represents a plausible but necessarily arbitrarily low value as $\mathrm{N}_{2}$ reduction rates are not well constrained.

\subsection{Marine sediment adsorption}

To model $\mathrm{NH}_{x}$ adsorption onto sediments, we used a Freundlich isotherm model, which relates the concentration of surface-adsorbed species to the concentration of dissolved species (Mackin and Aller, 1984):

$$
Q_{\mathrm{e}}=K_{\mathrm{f}} C_{\mathrm{e}}^{1 / n}
$$

where $Q_{\mathrm{e}}$ is the amount of solute adsorbed per mass of sediment at equilibrium (in $\mathrm{mol} \mathrm{g}^{-1}$ ), $C_{\mathrm{e}}$ is the equilibrium solution concentration (in $\mathrm{m} M$ ), $K_{\mathrm{f}}$ is an indicator of adsorption capacity, which depends on factors such as the number of available exchange sites per unit sediment mass or volume (the larger the value of $K_{\mathrm{f}}$, the more $\mathrm{NH}_{x}$ can be adsorbed), and $n$ is the Freundlich coefficient, which is an indicator of the strength of adsorption.

Generally $K_{\mathrm{f}}<1$, and $n<1$ (where $n$ is small, adsorption is strong). Both $n$ and $K_{\mathrm{f}}$ are system-specific constants. We used values of $n \sim 1$ and $K_{\mathrm{f}} \sim 10^{-3} \mathrm{~L} / \mathrm{g}$, derived from the work of Mackin and Aller (1984). Although mean ocean temperature as a function of time remains uncertain, the temperature dependence of $\mathrm{NH}_{x}$ adsorption on marine sediments has been found to be negligible over the range of 6$26^{\circ} \mathrm{C}$ (Mackin and Aller, 1984); thus a temperature term was not included in the model.

\subsection{Subduction and continental erosion}

The subduction flux of nitrogen may have changed over Earth's history, depending on subduction rates and the abundance of $\mathrm{N}$ in subducted sediments, but remains poorly constrained. Substantial amounts of nitrogen may be cycled into the deep mantle. It has been estimated that presently $\sim 3-6 \times 10^{10} \mathrm{~mol} \mathrm{~N} \mathrm{yr}^{-1}\left(4.2-8.4 \times 10^{8} \mathrm{~kg} \mathrm{~N} \mathrm{yr}^{-1}\right)$ is transported to the mantle by cold slabs (Busigny et al., 2003; Goldblatt et al., 2009).

While there may be a significant amount of nitrogen in sediment pore water, at the current rate of about $1 \mathrm{~km}^{3} \mathrm{yr}^{-1}$, it would take about 1.4 billion years to cycle the entire ocean volume through the world's accretionary prisms (Huene and Scholl, 1991). This is about 2 orders of magnitude slower than the present cycling time of the oceans through hydrothermal vents at mid-ocean ridges. Thus, the chemical processes associated with hydrothermal circulation at mid-ocean ridges likely have a larger effect on ocean $\mathrm{N}$ chemistry than do the low-temperature waters expelled from accretionary prisms.

The modern oceanic crust is recycled on average every $100 \mathrm{Ma}$ (e.g., Müller et al., 2008), subducting $\sim 1.34 \times 10^{7}$ to $2.1 \times 10^{10} \mathrm{~kg} \mathrm{~N} \mathrm{yr}^{-1}$. For the base scenario, we assume a constant subduction rate with a timescale of $100 \mathrm{Ma}$ for complete oceanic crust turnover. To consider the addition of nitrogen to the continental crust, we used a constant accretion efficiency factor $\epsilon$ which governs the fraction of the nitrogen subduction rate which is accreted to the continental mass (independent of the continental growth model). As this value is poorly constrained, and in order to retain the ability to draw general inferences using the model, we varied this parameter over the entire range from 0 to 1 :

$$
\begin{gathered}
F_{\text {sed-uma }}=(1-\epsilon) \frac{M_{\text {sed }}}{\tau} \\
F_{\text {sed-ccr }}=\epsilon \frac{M_{\text {sed }}}{\tau}
\end{gathered}
$$

where $M_{\text {sed }}$ is the mass of nitrogen in the sediments and $\tau$ the subduction rate.

Finally, continental nitrogen can be returned to the oceans by erosion. Estimates for modern continental erosion rates vary from $10^{-5}$ to $5 \times 10^{-5} \mathrm{~m} \mathrm{yr}^{-1}$ (Von Blanckenburg, 2005), with the total flux proportional to the continental surface area. By multiplying this value by the surface area of the continental crust as a function of time, we can compute the return flow of nitrogen species to the oceans.

\subsection{Mantle to atmosphere}

The present flux of nitrogen from Earth's mantle to the atmosphere has been variously estimated as $2.8-30 \times 10^{9}$ mol N $2 \mathrm{yr}^{-1}\left(7.84-42 \times 10^{7} \mathrm{~kg} \mathrm{~N} \mathrm{yr}^{-1}\right.$ ) (Marty, 1995; Sano et al., 2001). About $\sim 25 \mathrm{~km}^{3} \mathrm{yr}^{-1}$ of upper mantle material surfaces as magma, which is distributed as follows: $19 \%$ $\left(\sim 5 \mathrm{~km}^{3}\right)$ in arcs (with the majority of the $\mathrm{N}$ released as $\mathrm{N}_{2}$ ) and $81 \%\left(\sim 20 \mathrm{~km}^{3}\right)$ in mid-ocean ridge basalt (MORB) (with the majority of the $\mathrm{N}$ released as $\mathrm{NH}_{x}$ ) (Coffin et al., 2002). From the lower mantle, $\sim 2.5 \mathrm{~km} \mathrm{yr}^{-1}$ comes out in hot-spot volcanism, and we assume all of the $\mathrm{N}$ outgassed by this mechanism is $\mathrm{NH}_{x}$. It is worth noting that, given the present subduction estimates indicated in Section 2.5, the net flux of nitrogen between Earth's surface and interior could be in either direction. 
The present-day nitrogen distribution and flux values are assumed to be the outcome of both the nitrogen content and redox state of the mantle. We linearly scaled the bulk volcanic output in the model to the mantle nitrogen content divided by the present-day value as a reference. Mikhail and Sverjensky (2014) showed that, in aqueous fluids at conditions prevailing in Earth's upper mantle, nitrogen can be present either as $\mathrm{N}_{2}$ or $\mathrm{NH}_{x}$. Further, Li et al. (2015) also showed that nitrogen speciation in silicate melts strongly depends on oxygen fugacity. To asses the importance of this partitioning, we therefore varied the partition of upper mantle degassing between reduced species (MORB-like) and neutral (arc-like) with a redox parameter $\alpha_{\mathrm{m}}$, which is 0.19 for the present mantle (Sano et al., 2001). We did not consider the time dependence of this parameter in order to avoid extra complexity and simply analyzed a range of constant values. We also neglected how redox state would influence rock mineralogy and therefore the preferential retention of $\mathrm{NH}_{x}$ in the mantle.

A typical convection speed in the present-day mantle is on the order of $1-10 \mathrm{~cm} \mathrm{yr}^{-1}$, leading to mixing rates on the order of $10^{-9}$ to $10^{-8} \mathrm{yr}^{-1}$ (Ferrachat and Ricard, 1998; Van Keken and Zhong, 1999). There is significant uncertainty in these estimates, mostly due to unknown thermophysical properties at high-pressure, high-temperature conditions and potential chemical layering (Van Keken and Zhong, 1999); we therefore used values within this range as an estimate. We expect convection to be more vigorous early in Earth's history; thus we scaled mantle mixing as a decreasing exponential, as was done for ocean circulation. For this time dependence, we used $F_{0}=10^{-8}, F_{1}=3 \times 10^{-8} \mathrm{yr}^{-1}$, and $\tau=10^{9}$ yr. The model evolution can be seen in Fig. 2 d. We also considered cases with constant mixing rates to evaluate the importance of this parameter.

\section{Results}

In this section, we present the implications of nitrogen cycling on a planet with similar geodynamical processes as the modern Earth. First, we show the evolution resulting from "best guess" model parameters, as presented in the previous section, which includes an atmosphere with a high abiotic fixation rate and a mantle redox state similar to the present day, with evolving dependence on mantle mixing and ocean hydrothermal circulation rates. Then, we show the influence of those rates, initial conditions, and mantle redox state on the nitrogen content of the atmosphere and volcanic degassing fluxes.

\subsection{Representative evolution}

A typical simulation, with parameters described in Table 3, leads to the system evolution shown in Fig. 3 (high abiotic atmospheric fixation rate) and Fig. 4 (low abiotic atmospheric fixation rate). We start with a random distribution of initial conditions in phase space and integrate forward in time. Present terrestrial values are shown as dashed lines and correspond to a bulk silicate Earth content of $3.4 \times 10^{19} \mathrm{~kg} \mathrm{~N}$ (i.e., including all reservoirs except the core), as described in Table 1.

The main difference with the present-day Earth is the much larger nitrogen content in the oceans, mostly present as $\mathrm{NH}_{x}$. As a consequence, the mantle and continental crust
Table 3. Main Simulation Parameters and Their Default Values

\begin{tabular}{lcc}
\hline Name & Parameter & Default value \\
\hline Mantle redox state & $\alpha_{\mathrm{m}}$ & 0.2 \\
Atmosphere redox state & $\alpha_{\mathrm{a}}$ & 0.2 \\
Subduction rate & $D$ & $100 \mathrm{Ma}$ \\
Continental accretion & $\epsilon$ & 0.05 \\
Erosion rate & - & $5 \times 10^{-4} \mathrm{~m} \mathrm{yr}^{-1}$ \\
Ocean hydrothermal & & \\
$\quad$ circulation & & \\
$\quad$ Decay constant & $\tau$ & $150 \mathrm{Ma}^{\text {Min value }}$ \\
$\quad$ Max value & $F_{0}$ & $2.4 \times 10^{5} \mathrm{~kg} \mathrm{~N} \mathrm{yr}^{-1}$ \\
Mantle mixing rate & $F_{1}$ & $2.4 \times 10^{8} \mathrm{~kg} \mathrm{~N} \mathrm{yr}^{-1}$ \\
$\quad$ Decay constant & & \\
$\quad$ Min value & $\tau$ & $10^{9} \mathrm{yr}^{-1}$ \\
$\quad$ Max value & $F_{0}$ & $1 \times 10^{-8} \mathrm{yr}^{-1}$ \\
\hline
\end{tabular}

have lower nitrogen content than the modern Earth. It is interesting to note here that the ocean is the only reservoir that hosts all three nitrogen speciation types in abundance and therefore serves as a switchboard for the global balance. In the low abiotic fixation rate (Fig. 4), nitrogen is not fixed from the atmosphere robustly and therefore reaches several present atmospheric levels (PAL), leaving other reservoirs with much lower concentrations. Note that we do not plot the marine sediments reservoir content evolution as it is directly related to the oceanic $\mathrm{NH}_{x}$ concentration according to Eq. 3, but it can hold a few PAL nitrogen, as shown in Table 4.

Two evolutionary timescales can be observed. The first characterizes the time required for the system to "forget" its initial conditions, which is about $500 \mathrm{Ma}$ in Fig. 3 and several billion years in Fig. 4. The second is a long-term system evolution governed by environmental properties. This can be understood in terms of approach to steady state and the evolution of the steady state itself. In the high abiotic fixation rate case, only a few hundred million years are necessary to reach the steady state defined by the model parameters from a wide range of initial conditions. Then, as ocean and mantle mixing rates and the impact flux decrease with time (see Fig. 2), the steady state varies and is tracked by the actual state of the system (i.e., the long-term evolution). This is more visible in the high abiotic atmospheric fixation rate case (Fig. 3) because of the faster cycling timescales throughout the network, but initial condition collapse also happens, although less dramatically, in the low abiotic atmospheric fixation case (Fig. 4).

Figure 5 shows a random selection of trajectories in the phase space between atmospheric $\mathrm{N}_{2}$ ( $x$ axis) and upper mantle $\mathrm{NH}_{x}$ ( $y$ axis) for the high abiotic fixation case. As suggested in Figs. 3-4, irrespective of the initial conditions, the nitrogen distribution is attracted to a steady state determined by the system parameters (upper mantle redox state, ocean hydrothermal circulation, and mantle mixing rates, etc.).

Our initial conditions are randomly distributed in phase space; therefore early evolution corresponds to the relaxation of those initial conditions on a self-consistent track for a given set of model parameters. Interestingly, this common 

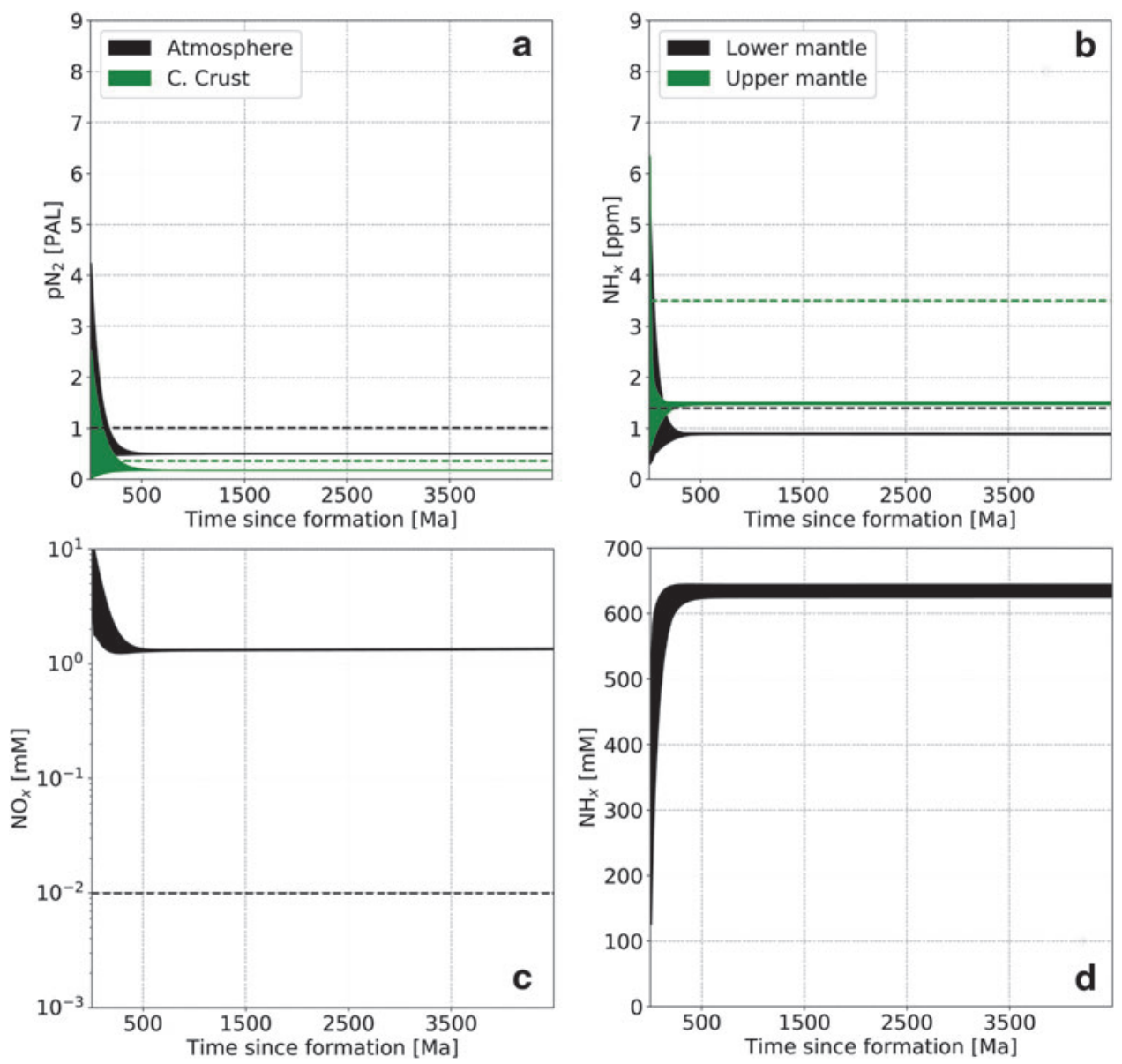

FIG. 3. Nitrogen content as a function of time in the main reservoirs for a high abiotic atmospheric fixation rate. (a) Atmospheric $\mathrm{N}_{2}$, (b) upper and lower mantle $\left(\mathrm{NH}_{x}\right)$, dissolved oceanic $\mathrm{NO}_{x}(\mathbf{c})$ and $\mathrm{NH}_{x}(\mathbf{d})$. Dashed lines represent presentday values. For oceanic $\mathrm{NH}_{x}$ this value is $3 \times 10^{-4} \mathrm{~m} M$ and therefore does not appear on the figure. The randomly seeded range of initial conditions all collapse on the same evolutionary trend during the first $\sim 500$ Ma (see also Fig. 5).

evolutionary track is reached quickly, allowing for major distribution changes early in system evolution.

\subsection{Parameter sensitivity}

Figure 6 shows the steady state $\mathrm{pN}_{2}$ as a function of mantle mixing and ocean hydrothermal circulation rates for the high abiotic atmospheric fixation rate scenario. The two limiting cases of "no mixing" and "perfect mixing" can be seen as the asymptotes of the different curves (note that the two parameters were varied independently here). A low mantle convection rate favors a larger atmospheric $\mathrm{N}_{2}$ content as more nitrogen is degassed through arc systems as $\mathrm{N}_{2}$. Conversely, more effective mantle mixing increases the fraction of nitrogen degassed by hot-spot volcanism, which is more reduced (and therefore eventually dissolves as oceanic $\mathrm{NH}_{x}$ ).

The ocean hydrothermal circulation rate controls the fraction of ocean water that is circulated through hydrothermal vents per year. A high circulation rate favors efficient circulation of nitrogen between the different reservoirs, as oceanic nitrogen is readily reduced and subducted. The outcome is a larger atmospheric $\mathrm{N}_{2}$ content. Low values, however, prevent effective burial to the mantle and therefore also imply a lower degassing rate to the atmosphere.
We can now examine how the steady state nitrogen distribution between various reservoirs varies with the redox state of the upper mantle and atmosphere. Increasing the mantle redox state (Fig. 7) controls the fraction of mantle nitrogen released by volcanism as $\mathrm{N}_{2}$ (arc-like) versus $\mathrm{NH}_{x}$ (MORB-like). Figure 7 shows that, when the mantle is more oxidized, the atmospheric $\mathrm{N}_{2}$ content increases, which subsequently forces an increase in both oceanic dissolved $\mathrm{N}_{2}$ (through Henry's law) and $\mathrm{NO}_{x}$ (through abiotic fixation). This confirms that upper mantle redox state, or more specifically the partitioning of volcanic gases between reduced and oxidized species, can control the long-term state (pressure and composition) of the atmosphere. Note here that $\alpha_{\mathrm{m}}$ cannot be directly related to redox buffers such as fayalitemagnetite-quartz as it is only an effective partitioning between volcanic degassing fluxes, although this could be modeled separately.

The oceanic crust subduction timescale and continental crust erosion timescale both play a large role in determining the final distribution of nitrogen between the existing reservoirs. Figure 8 shows the atmospheric nitrogen content at the present day as a function of erosion rate for various accretion efficiencies (left) and subduction timescales (right). Higher erosion rates always increase the amount of atmospheric 

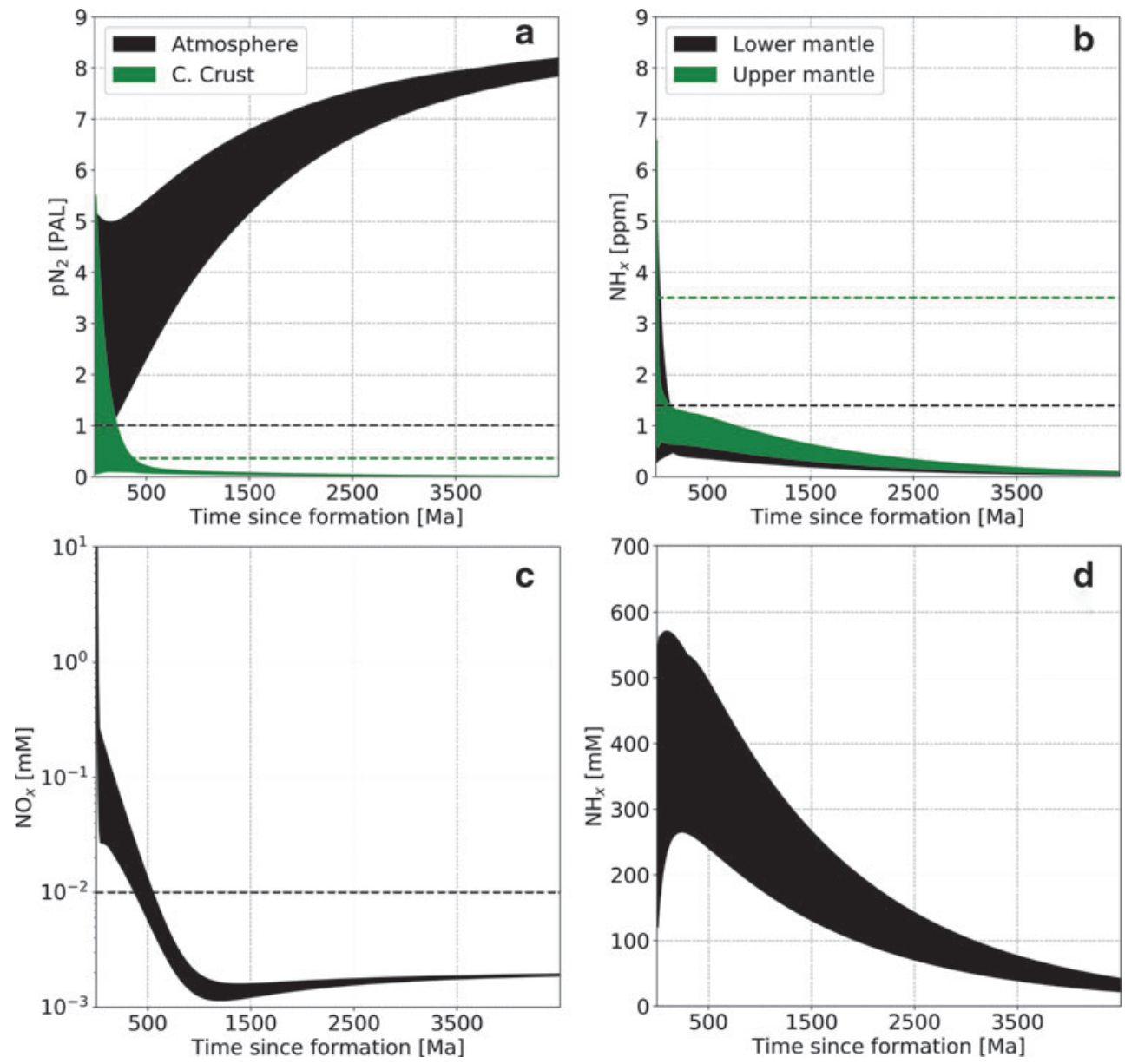

FIG. 4. Nitrogen content as a function of time in the main reservoirs for a low abiotic fixation rate. (a) Atmospheric $\mathrm{N}_{2}$, (b) upper and lower mantle $\left(\mathrm{NH}_{x}\right)$, dissolved oceanic $\mathrm{NO}_{x}(\mathbf{c})$ and $\mathrm{NH}_{x}(\mathbf{d})$. Dashed lines represent present-day values. For oceanic $\mathrm{NH}_{x}$ this value is $3 \times 10^{-4} \mathrm{~m} M$ and therefore does not appear on the figure. The randomly seeded range of initial conditions take several billion years to collapse on the same evolutionary trend (see also Fig. 5).

nitrogen as it prevents efficient storage of nitrogen in the continental crust. Lower accretion efficiency has the same effect on nitrogen distribution. Irrespective of accretion efficiency, faster subduction decreases the average residence time of nitrogen in the oceanic crust and also leads to higher atmospheric nitrogen content.

The main result of this study is that, given a high abiotic fixation rate and a partition of volcanism type similar to today's (i.e., $19 \%$ degassing from the upper mantle as $\mathrm{N}_{2}$ in arctype volcanism, with the remaining $81 \%$ degassed as $\mathrm{NH}_{x}$

Table 4. Average Mass Balance CORRESPONDING TO FIGURES 3 AND 4

\begin{tabular}{lcc}
\hline Reservoir & Figure 3 & Figure 4 \\
\hline Atmosphere & 0.50 & 8.00 \\
Continental crust & 0.17 & 0.01 \\
Marine sediments & 3.05 & 0.14 \\
Oceans $\mathrm{N}_{2}$ & 0.00 & 0.04 \\
Oceans $\mathrm{NO}_{x}$ & 0.02 & 0.00 \\
Oceans $\mathrm{NH}_{x}$ & 3.82 & 0.18 \\
Upper mantle & 0.36 & 0.02 \\
Lower mantle & 0.56 & 0.03 \\
\hline
\end{tabular}

All values are in PAL. from MORB-like volcanism, and all hot-spot-like volcanism from the lower mantle reduced), our global nitrogen cycling model predicts a significant increase in oceanic $\mathrm{N}$ content over time, while atmospheric $\mathrm{N}_{2}$ content remains lower than today. The situation is different in the low abiotic fixation case. In that scenario, the previous observations still hold; but the atmosphere also acts as a bottleneck, and the initial oceanic $\mathrm{NH}_{x}$ reservoir is slowly transferred back to $\mathrm{N}_{2}$ in the atmosphere, where no process is able to mobilize it fast enough to prevent buildup. Another worthwhile observation is that the residence time of nitrogen in most reservoirs is small compared to geological times; therefore we expect large variations during early planetary evolution, as the system reaches steady state. In the next section we discuss the interpretation of these results and important limitations of the model.

\section{Discussion}

There are important caveats to be aware of before interpreting the outcome of this model. We present the major ones below but stress again what this model attempts to achieve. We chose a selection of fluxes and respective parameterizations that best match our understanding of presentday terrestrial abiotic nitrogen fluxes. The model is then integrated forward in time from planetary differentiation to 


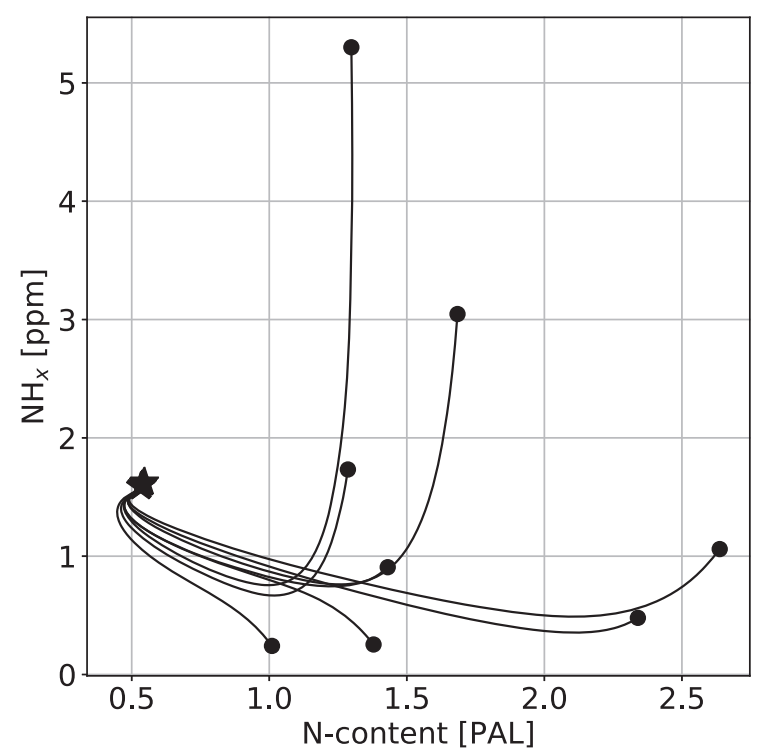

FIG. 5. Example of evolutionary curves in the atmospheric $\mathrm{N}_{2}$ ( $x$ axis)/upper mantle $\mathrm{NH}_{x}$ ( $y$ axis) plane for the model presented in Fig. 3. Circles denote initial conditions and the star the common final state. Every simulation joins the common evolutionary track in less than $500 \mathrm{Ma}$.

the present day to obtain insight into what such processes imply for nitrogen distribution. Using this result to describe an "abiotic Earth" is more difficult, and we can only claim to model nitrogen cycling on a planet with similar geodynamical features as Earth.

\subsection{Limits of the model}

To that end, several simplifying assumptions had to be made. This model does not specifically take into account chemical reactions between gas-phase $\mathrm{N}$-containing species and other atmospheric species such as $\mathrm{C}$-containing gases (e.g., $\mathrm{CO}_{2}, \mathrm{CO}$, and $\mathrm{CH}_{4}$ ), though these could have a marked impact on some of the fluxes. For example, the oxidation state and pressure of $\mathrm{C}$-containing gases govern the nature of $\mathrm{N}$ transformations in the atmosphere $\left(\mathrm{a} \mathrm{CH}_{4}\right.$-dominated

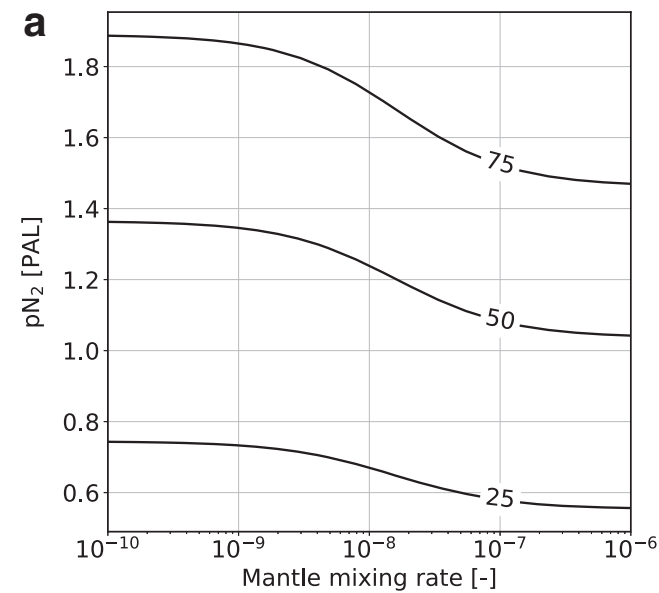

atmosphere is prone to generating $\mathrm{HCN}$ and $\mathrm{NH}_{3}$, while a $\mathrm{CO}_{2}$-dominated atmosphere tends to predominantly generate $\mathrm{NO}_{x}$ species [Folsome et al., 1981; Heinrich et al., 2007; Cleaves et al., 2008]).

High pressures of $\mathrm{CO}_{2}$ can also have major effects on temperature and seawater $\mathrm{pH}$, as well as Henry's law constants for the partitioning of atmospheric $\mathrm{N}$-species. For $\mathrm{N}_{2}$ and $\mathrm{NO}_{x}$ species this is likely not problematic, as $\mathrm{N}_{2}$ does not ionize in water and nitrite and nitrate are highly soluble across all reasonable $\mathrm{pH}$ values.

This model assumes that surface temperatures allow liquid oceans to exist, which are not predominantly ice covered. This is important with regard to $\mathrm{N}$ speciation as so many of the higher- and lower-oxidation-state species of $\mathrm{N}$ are water soluble. Global N-cycling cannot be entirely decoupled from the global hydrologic cycle (Barron et al., 1989), which will be investigated in a subsequent study.

Other potentially important nitrogen fixation mechanisms (in this case yielding $\mathrm{HCN}$, which hydrolyzes ultimately to formic acid and ammonia [Miyakawa et al., 2002]) are extreme-UV solar radiation (Zahnle, 1986) and coronal mass ejections from the young Sun (Airapetian et al., 2016). They are both estimated to be more efficient in a reducing atmosphere and may have helped fix a large fraction of early atmospheric $\mathrm{N}_{2}$. We did not model these processes, but we have shown that our results do not greatly depend on initial conditions; therefore they may be neglected over the long term. However, these processes may be important when considering the early availability of nitrogen for potential biotic processes.

The volume of the oceans is thought to have changed over time but was kept constant in our base simulations. It has been variously estimated that the volume of the oceans has decreased by as much as $60 \%$ since their formation (Korenaga, 2008), though other authors have suggested a general increase in their volume over the same time (Harrison, 1999; Pope et al., 2012). In our model, this would mainly influence the amount of $\mathrm{N}_{2}$ that can be dissolved in them. If volume change also influences the effective hydrothermal circulation rate, it may play a more important role, as can be appreciated from Fig. 6 (simulations including volume change are also presented in Appendix B).

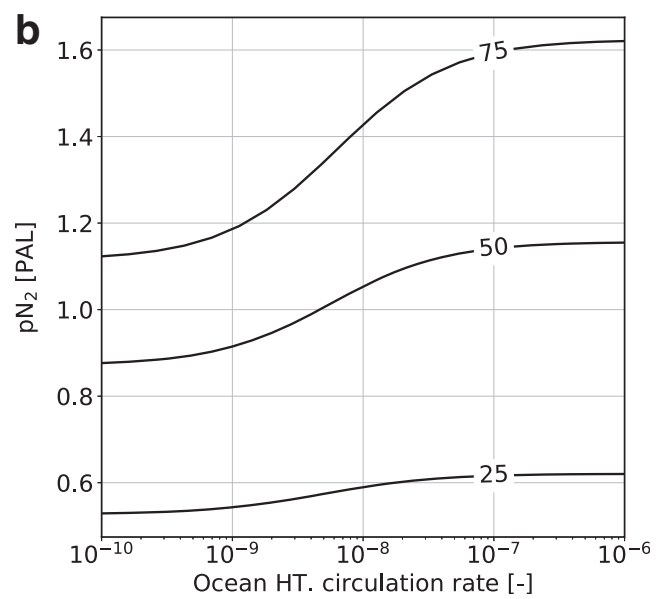

FIG. 6. Atmospheric nitrogen content after $4.5 \mathrm{Ga}$ as a function of (a) mantle mixing rate and (b) ocean hydrothermal circulation rate for different values of $\alpha_{\mathrm{m}}$ in the high abiotic atmospheric fixation rate case. The parameter $\alpha_{\mathrm{m}}$ controls the partitioning between different volcanic degassing styles; see the text for more details. 

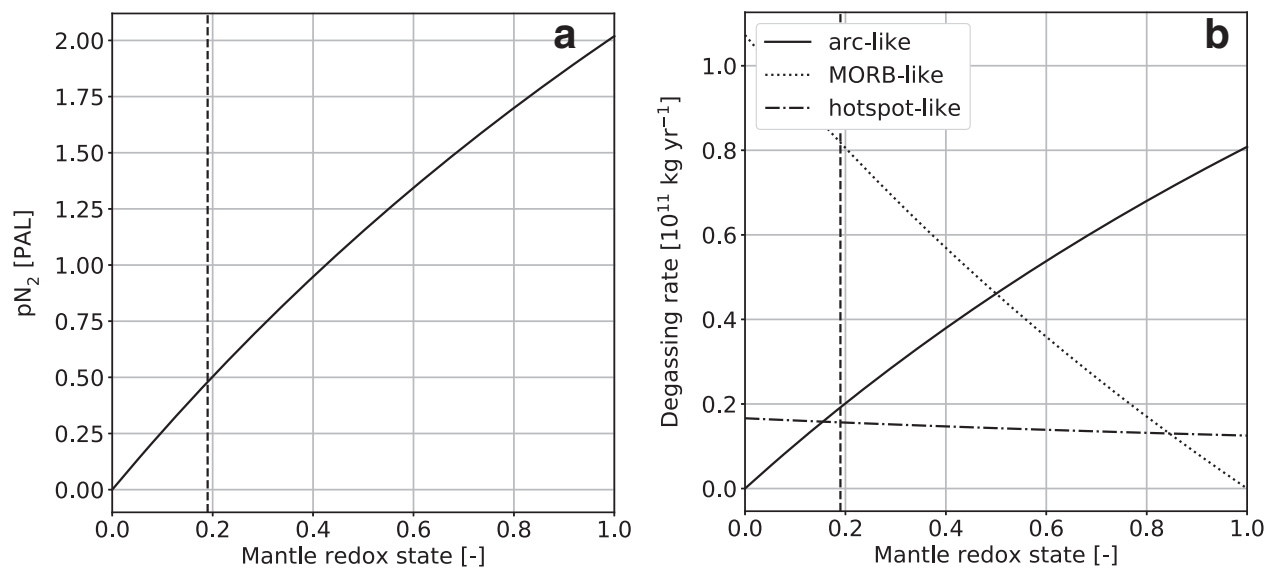

FIG. 7. (a) Atmospheric nitrogen content and (b) volcanic degassing rate as a function of mantle redox state $\alpha_{\mathrm{m}}$ after $4.5 \mathrm{Ga}$ for the high abiotic atmospheric fixation rate case. The redox state controls the relative contribution of arc-like (high values, degassed as $\mathrm{N}_{2}$ to the atmosphere) to MORB-like (low values, degassed as $\mathrm{NH}_{x}$, which rains out instantaneously to the oceans) volcanic degassing. The vertical dashed line represents the value estimated for present-day Earth.

We do not consider the potential sequestration of $\mathrm{N}$ species in ice caps or loss to space. The quantity of nitrogen trapped in ice on the modern Earth is estimated to be $\sim 2.6 \times 10^{11} \mathrm{~kg}$ (Wolff, 1995), which is orders of magnitude less than other reservoirs. As $\mathrm{N}_{2}$ is a relatively heavy gas, the terrestrial loss rate due to sputtering and thermal escape is also assumed to be negligible with some caveats; see for example the work of Shizgal and Arkos (1996) or Lammer et al. (2011).

Another effect that we did not model is the influence of the atmosphere on surface temperature. This represents a coupled feedback which may be important when considering specific planetary configurations. However, tripling the amount of $\mathrm{N}_{2}$ in the atmosphere is estimated to give a 3-8 K increase in mean surface temperature, which would negligibly affect Henry's law constants, adsorption isotherms (Goldblatt et al., 2009), or erosion rates (Bland and Rolls, 1998). Thus, variations in atmospheric $\mathrm{N}_{2}$ content could create oscillatory dynamics in temperature and nitrogen cycling too fine to be discovered by this simple model.

This model assumes a constant marine sediment mass of fixed composition and fixed adsorption capacity. The uncertainty in this parameter may be large (see for example the discussion in Veizer [1973]), and sediment volume is generally related to the age of underlying oceanic crust (Hay et al., 1988). In fact, the seafloor is very heterogeneously covered in sediments of varying ages, depths, and composition, and marine sedimentation is related to continental growth and biological activity (McLennan and Taylor, 1983). It is possible there was relatively little sediment present in the earliest oceans, and the facility of subducting adsorbed nitrogen was consequently lower. The composition and adsorption capacity of global marine sediments over deep time is as yet poorly constrained.

Several other potentially important contributions were also not considered in this study. These were neglected in order to keep the model tractable, but as they become more constrained, their impact on global cycling should be assessed. Here, we provide order-of-magnitude estimates and possible trends based on first-order considerations.

Metamorphism in the continental crust is a direct source of $\mathrm{N}_{2}$ for the atmosphere. Assuming $75 \%$ of nitrogen is releasable by metamorphism (Boudou et al., 2008), and this metamorphism occurs over a billion-year timescale, this could provide a return flux to the atmosphere on the order of
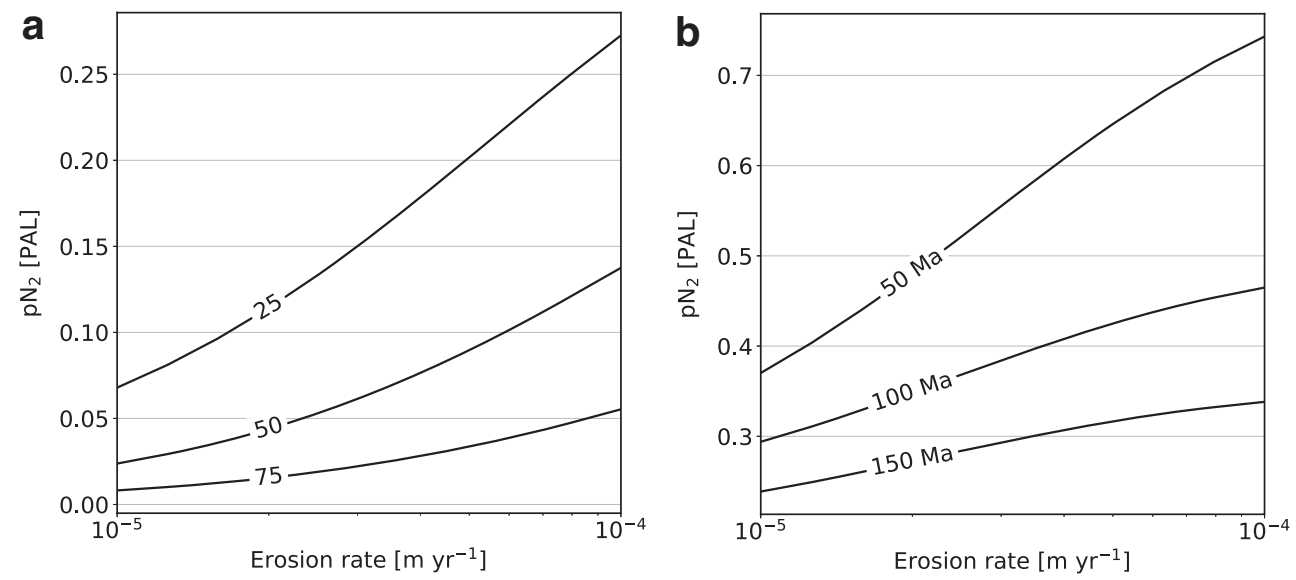

FIG. 8. Atmospheric nitrogen content after $4.5 \mathrm{Ga}$ as a function of erosion rate for different values of (a) continental accretion efficiency $\epsilon$ and (b) oceanic crust subduction timescale (parameter $D$ from Table 3 ). 
$10^{9} \mathrm{~kg} \mathrm{~N} \mathrm{yr}^{-1}$, which is smaller than other modeled fluxes, which are on the order of $10^{10}$ to $10^{11} \mathrm{~kg} \mathrm{~N} \mathrm{yr}^{-1}$. However, if the average age of metamorphosed rocks is much shorter (e.g., 100 Ma), this flux becomes greater by an order of magnitude and will play a larger role, with the net effect of increasing $\mathrm{pN}_{2}$ and decreasing the amount of $\mathrm{N}$ sequestered in the continental crust.

Another potential source of $\mathrm{N}_{2}$ back to the atmosphere is reaction of odd nitrogen species in the oceans. Abiotic reactions of dissolved odd nitrogen species are suspected to play an important role in the nitrogen cycle (Zhu-Barker et al., 2015), and it seems likely that there would have been a rich variety of aqueous chemistry in the primitive oceans that would have impacted the dynamics of these species. Acknowledging that we do not differentiate between $\mathrm{HNO}_{2}$ and $\mathrm{HNO}_{3}$ for $\mathrm{NO}_{x}$ species, or for example between ammonia and hydrazine for $\mathrm{NH}_{x}$ species, we can nevertheless place upper limits on the rates that may affect the principle reactive species.

An especially potentially important reaction in this regard is that of aqueous ammonium nitrite to give $\mathrm{N}_{2}$ and $\mathrm{H}_{2} \mathrm{O}$ (Nguyen et al., 2003). Solving the rate equation for a modern ocean $\mathrm{pH}$ value $(\sim 8)$ and $25^{\circ} \mathrm{C}$ gives a rate of $\mathrm{N}_{2}$ evolution by this mechanism of $\sim 4.5 \times 10^{-9} M^{-2} \mathrm{yr}^{-1}$. Assuming typical concentrations estimated here gives annual $\mathrm{N}_{2}$ return fluxes from the oceans to the atmosphere of $\sim 5.2 \times 10^{2}$ to $2.6 \times 10^{12} \mathrm{~kg} \mathrm{~N} \mathrm{yr}^{-1}$, depending on the ratios of reactant species. While we expect $\mathrm{HNO}_{2}$ to be less abundant than $\mathrm{HNO}_{3}$, and thus for these to be upper boundaries on return rates, this does point to the potential extreme importance of low-temperature aqueous phase chemistry to an overall abiotic N-cycle.

There are undoubtedly many other potential reactions that deserve exploration, such as photochemistry in surface waters and redox disproportionation with dissolved transition metal species, such as iron (II) and (III) (Zhu-Barker et al., 2015). Such considerations are seriously hampered by the complexities of aqueous geochemistry and uncertainties regarding the abundance of dissolved metal ions and carbonate species (e.g., which influence $\mathrm{pH}$ and could precipitate iron (II) as siderite) in the primitive oceans, as well as uncertainties in the global average ocean $\mathrm{pH}$ and temperature, or how these values may have changed over time.

Finally, the nature of mantle mixing and differentiating between degassing of primordial nitrogen versus degassing of subducted nitrogen is beyond the scope of this model. Tracking of isotopic differences could be added to this model to add to the ways it can be compared to observations. This may also help understand partitioning between different types of degassing rates.

\subsection{Implications for Earth}

In both the low and high abiotic atmospheric fixation rate scenarios, a key feature of our model is the large $\mathrm{NH}_{x}$ reservoir in the oceans. None of the processes modeled here are able to cycle it back to the mantle fast enough to match values similar to that of the present-day Earth. A potential implication is that the net effect of biotic processes is to use this easily available nitrogen source for biomass production, increasing the flux of nitrogen transported to the continental crust and mantle through enhanced sedimentation. If the low abiotic fixation rate case is more representative, life may be the missing conduit that bypasses the atmospheric bottleneck (i.e., the fact that sources to the atmospheric nitrogen budget are much greater than its sinks) and efficiently redistributes $\mathrm{N}_{2}$ back into global reservoirs.

Another observation can be made that relates to measurements that have estimated total atmospheric pressure to have been less than 0.5 PAL 2.7 billion years ago (Som et al., 2016). It is interesting to note that, for the high abiotic atmospheric fixation rate case, the net effect of life would be to add $\mathrm{N}_{2}$ back to the atmosphere, and denitrification would have to become a major flux later than $2.7 \mathrm{Ga}$. On the other hand, for the low abiotic atmospheric fixation rate case, the net effect of life would be to draw $\mathrm{N}_{2}$ down from the atmosphere, and in that case biotic N-fixation would have to start earlier (and possibly considerably earlier) than $2.7 \mathrm{Ga}$ such that it would match paleo-pressure estimates. Note, however, that Marty et al. (2013) estimated $\mathrm{pN}_{2}$ to be similar to present-day value 3-3.5 billion years ago, so either large fluctuations have occurred over geological time or better constraints on $\mathrm{pN}_{2}$ and total atmospheric pressure as a function of time are required.

\subsection{Implications for remote sensing}

The main difference between this and previous models is the explicit treatment of the oceans and different speciations of nitrogen. In agreement with the work of Stüeken et al. (2016), we find that the overall trend of an abiotic planet with geological processes similar to those of Earth is longterm increase in $\mathrm{pN}_{2}$. However, depending on the lightninginduced abiotic fixation rate, the long-term evolution is different. For high abiotic fixation rates, the atmospheric $\mathrm{N}_{2}$ variation is limited to $10-20 \%$ of the atmospheric mass, and therefore it may not lead to any observable effect within error bars, as pointed out by Zhang and Zindler (1993); whereas for low abiotic fixation rates, there is a significant buildup of nitrogen in the atmosphere. In both cases, however, there is a large amount of nitrogen stored in the oceans as soluble $\mathrm{NH}_{x}$.

This study suggests that, if little nitrogen is observed in an atmosphere relative to an expected bulk content (for instance using $\mathrm{N}_{2}-\mathrm{N}_{2}$ collisions [Schwieterman et al., 2015]), and loss to space can be excluded, the bottleneck to global cycling is located in another reservoir besides the atmosphere. For a planet with geophysical parameters similar to those of Earth, this bottleneck is likely the flux back to the mantle (i.e., due to the lack of plate tectonics, or poor adsorption/subduction efficiency). In contrast, if a large fraction of the expected nitrogen budget is found in the atmosphere, our model suggests that it is due to a low atmospheric abiotic fixation rate. If atmospheric chemistry does not make that explanation probable, then it may suggest particularly efficient transport of nitrogen from the crust to a relatively oxidized mantle.

Another implication is that large variations in nitrogen content of a given reservoir do not necessarily imply a qualitative change in processes (e.g., the onset of plate tectonics, an oxygenation event). We found that the collapse of initial conditions to the model steady state takes a few hundred million years and may be non-monotonic, which comes from the fact that arbitrary initial conditions may be 
far from the long-term evolutionary trend. This also implies that, in cases where the early evolution is important, the choice of initial conditions plays an important role in the expected distribution of nitrogen species among planetary reservoirs.

\section{Conclusions}

In the absence of life, nitrogen is still actively redistributed among reservoirs by abiological planetary dynamics and processes. Understanding what controls this cycling can therefore be used as a remote observable for planetary dynamics and could help identify inhabited planets. In particular, understanding what controls the global fraction of nitrogen degassed to the atmosphere (e.g., geophysical and geochemical vs. biological processes) can help remote sensing observations make inferences about surface and interior processes.

This model suggests that the timescales involved in the evolution of $\mathrm{N}$ cycling allow a planet's geodynamical system to closely track predictable steady states, and it suggests that the long-term evolution of $\mathrm{N}$ cycling is governed by variations in the steady state due to environmental parameters. We have shown that changes in dynamical parameters (such as ocean hydrothermal circulation or mantle mixing rates, subduction rate, mantle and atmosphere redox state, etc.) lead to direct changes in nitrogen distribution and therefore that remote sensing of this distribution (as seen in atmospheric $\mathrm{N}_{2}$ content) can, in principle, be related to these parameters, as also suggested by Stüeken et al. (2016).

Assuming that the bulk nitrogen content of a planet can be estimated (from planetary formation considerations and stellar properties), and the age of a planetary system can be obtained from observation of its host star, the amount of $\mathrm{N}$ present in a planet's atmosphere could in principle be used to draw inferences about surface and interior processes, such as ocean volume, mantle mixing rate and redox state, the existence of plate tectonics, and the presence of life.

For example, if most of an abiotic planet's nitrogen is in its atmosphere, this implies there is no efficient transport
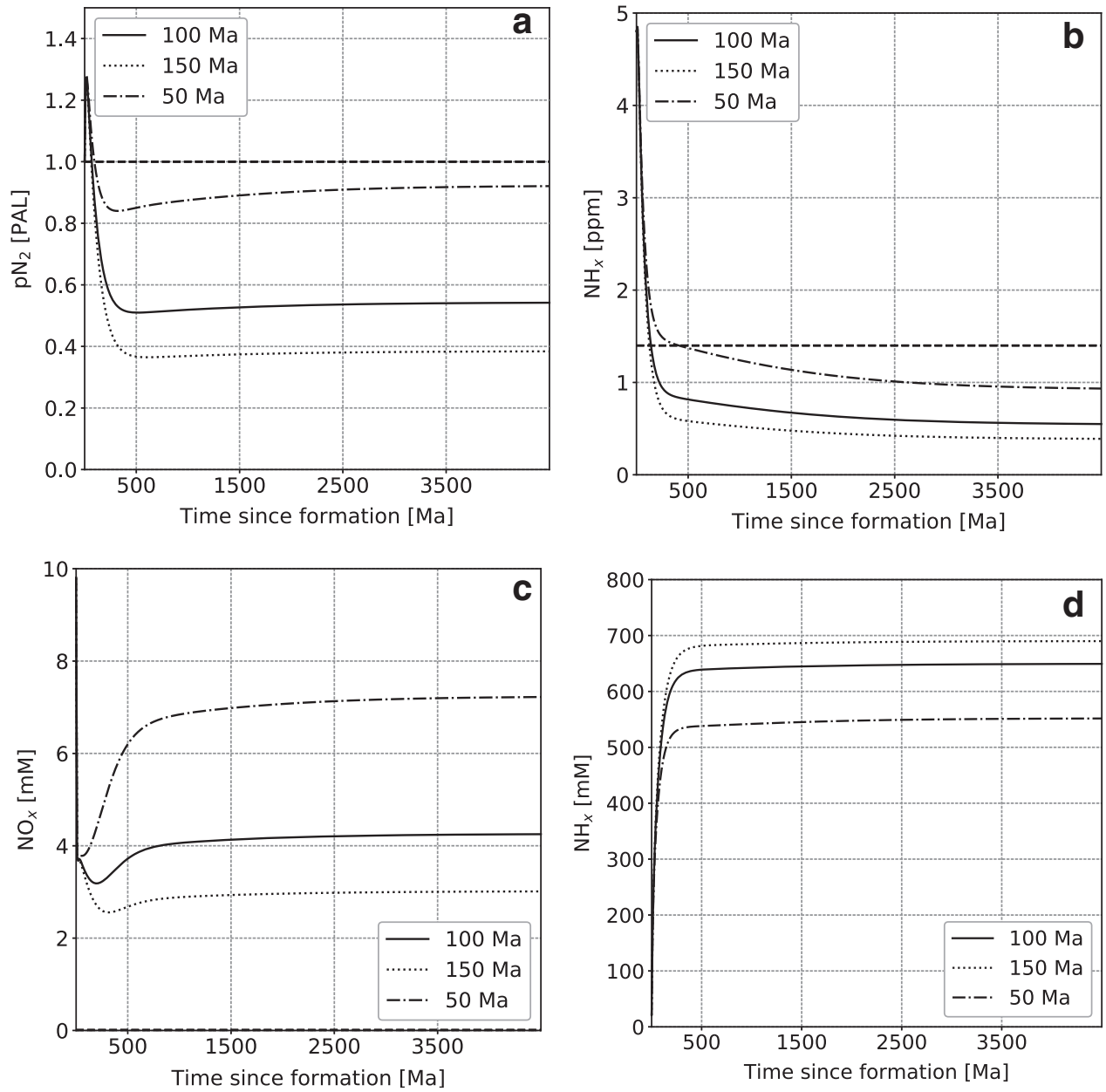

FIG. B1. Nitrogen content as a function of time in the main model reservoirs for different average oceanic crust subduction rates. (a) Atmospheric $\mathrm{N}_{2}$, (b) lower mantle $\left(\mathrm{NH}_{x}\right)$, oceanic $\mathrm{NO}_{x}$ (c) and $\mathrm{NH}_{x}$ (d). Dashed lines represent present-day values. For oceanic $\mathrm{NO}_{x}$ and $\mathrm{NH}_{x}$ these values are $10^{-2}$ and $3 \times 10^{-4} \mathrm{mM}$, respectively, and therefore do not appear on the figures. 
to the interior, which can be due to lack of plate tectonics or no hydrologic cycle. Any amount below this can be used to estimate the magnitude of cycling between surface and interior. This model is obviously very simple but benefits from the fact that $\mathrm{N}_{2}$ is remarkably chemically inert and its chemistry therefore relatively unaffected by the many nuances that would be extremely important for elements such as carbon or sulfur. There may be other elements or species not considered here whose dynamics are also, and possibly more, useful as indicators of biology on planets beyond Earth; however, $\mathrm{N}$ may be unique in this regard.

\section{Appendix A. Nitrogen Distribution}

Samples of a large number of carbonaceous chondrite meteorites give a mean nitrogen content of $3180 \mathrm{ppm}$ (McDonough and Sun, 1995), although many have lower abundances (Johnson and Goldblatt, 2015). Given that the mass of Earth is $\sim 6 \times 10^{24} \mathrm{~kg}$, this gives $0.7-1.9 \times 10^{19} \mathrm{~kg}$ total nitrogen (Table 1). An approximate inventory of $\sim 10^{19} \mathrm{~kg} \mathrm{~N}$ is commonly cited (Capone et al., 2006), though values of $2.0-3.3 \times 10^{20} \mathrm{~kg} \mathrm{~N}$ have also been offered (Johnson and Goldblatt, 2015). The variability in these estimates largely reflects uncertainties in the nitrogen content of the core.

Deep reservoirs likely play host to the largest amount of Earth's nitrogen. Recent high-pressure studies indicate that minerals such as $\beta-\mathrm{Fe}_{7} \mathrm{~N}_{3}$ are stable under deep Earth conditions and that the core could contain $\mathrm{Fe}_{x} \mathrm{~N}_{y}$ phases accounting for a massive $9.8 \times 10^{18} \mathrm{~kg} \mathrm{~N}$ (Minobe et al., 2015), or $\sim 50 \%$ of a proposed chondrite-derived inventory.

The average concentration of nitrogen in mantle-derived rocks has been estimated as between 0.2-2.1 ppm (Johnson and Goldblatt, 2015) and 2.8 + 1.0/-0.8 ppm (Marty, 1995). Given that the volume of the mantle is $\sim 1.2 \times 10^{7} \mathrm{~km}^{3}$, and its density is $\sim 4000 \mathrm{~kg} \mathrm{~m}^{-3}$, there is expected to be $3.4 \times 10^{18} \mathrm{~kg} \mathrm{~N}$ in the mantle, or approximately $20 \%$ of a proposed chondrite-derived inventory. There is also considerable uncertainty in this value; for comparison, Zhang
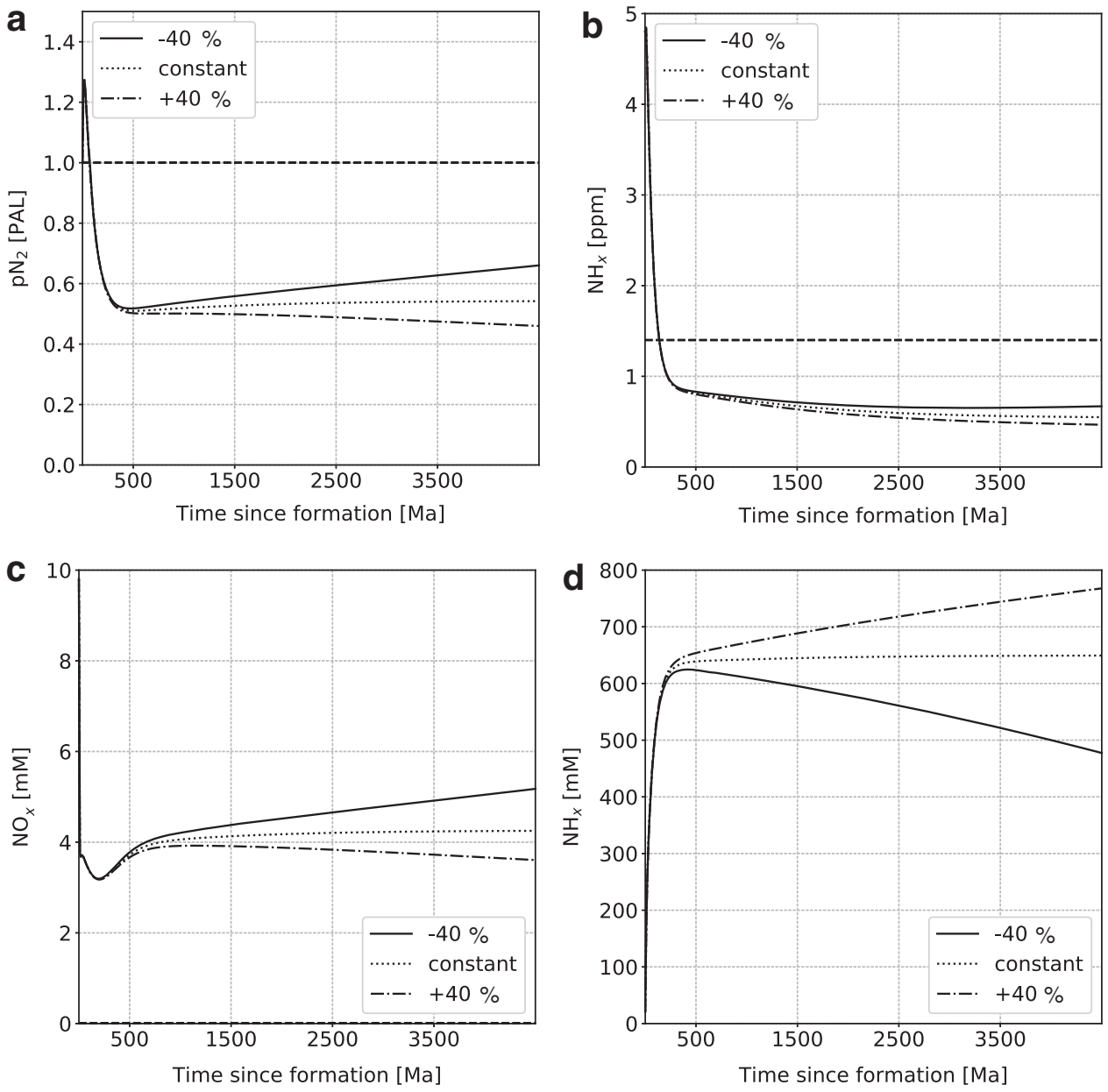

FIG. B2. Nitrogen content as a function of time in the main model reservoirs for different ocean volume evolution scenarios (values are given in percent change since formation). (a) Atmospheric $\mathrm{N}_{2}$, (b) lower mantle $\left(\mathrm{NH}_{x}\right)$, oceanic $\mathrm{NO}_{x}$ (c) and $\mathrm{NH}_{x}$ (d). Dashed lines represent present-day values. For oceanic $\mathrm{NO}_{x}$ and $\mathrm{NH}_{x}$, these values are $10^{-2}$ and $3 \times 10^{-4}$ $\mathrm{m} M$, respectively, and therefore do not appear on the figures. 
and Zindler (1993) estimated that the amount of $\mathrm{N}_{2}$ in the present mantle is $2.5 \times 10^{19} \mathrm{~mol}\left(7 \times 10^{17} \mathrm{~kg} \mathrm{~N}\right)$. Several authors have estimated that the vast majority of this nitrogen is at the -3 or 0 oxidation state ( $\mathrm{Li}$ and Keppler, 2014; Mikhail and Sverjensky, 2014). On the other hand, using NAr geochemistry, Johnson and Goldblatt (2015) showed that the present-day mantle likely contains $7 \pm 4$ PAL nitrogen $\left(2.8 \pm 1.6 \times 10^{19} \mathrm{~kg} \mathrm{~N}\right)$.

Earth's surface reservoirs, including the atmosphere, crust, oceans, and sedimentary rocks, are more amenable to direct measurement, and it is estimated that together they contain $5.9 \times 10^{18} \mathrm{~kg} \mathrm{~N}$ (Johnson and Goldblatt, 2015). There is estimated to be $4 \times 10^{18} \mathrm{kgN}$ in the atmosphere (e.g., Johnson and Goldblatt [2015] gave a value of $3.87 \times 10^{18} \mathrm{~kg}$ ). Together, the atmosphere and mantle account for $\sim 15 \%$ of a proposed chondrite-derived inventory. It is estimated there is an additional $1.9 \times 10^{18} \mathrm{~kg} \mathrm{~N}$ in the crust, oceans, and sedimentary rocks (Johnson and Goldblatt, 2015), accounting for an additional 5\% of the chondritic estimate. It is worth noting, for reference, that if all the nitrogen in contemporary surface reservoirs was dissolved in oceans of the current volume, a solution $\sim 0.2 \mathrm{M}$ in single
$\mathrm{N}$-atom containing species (e.g., ammonium, nitrite or nitrate) would be obtained (Schwartz, 1981).

\section{Appendix B. Appendix Figures}

\section{Appendix B.1. Subduction rate}

We varied the subduction rate by a factor of 3 to sample a plausible range of values (Fig. B1). For the fastest case (complete oceanic crust recycling in $50 \mathrm{Ma}$ ), the atmospheric $\mathrm{N}_{2}$ content is maximal, which is associated with a decrease of $\mathrm{NH}_{x}$ in the ocean, as more is adsorbed and subducted. In contrast, for the largest value (complete cycling in $150 \mathrm{Ma}$ ), a larger fraction of nitrogen remains in the oceans as $\mathrm{NH}_{x}$. A fast cycling rate also favors transport of nitrogen to the interior, which induces stronger degassing, as can be seen in the ocean $\mathrm{NO}_{x}$ content.

\section{Appendix B.2. Ocean volume}

The change in ocean volume as a function of time is uncertain. We therefore tested scenarios with a linear change of volume over time (Fig. B2). An increase in
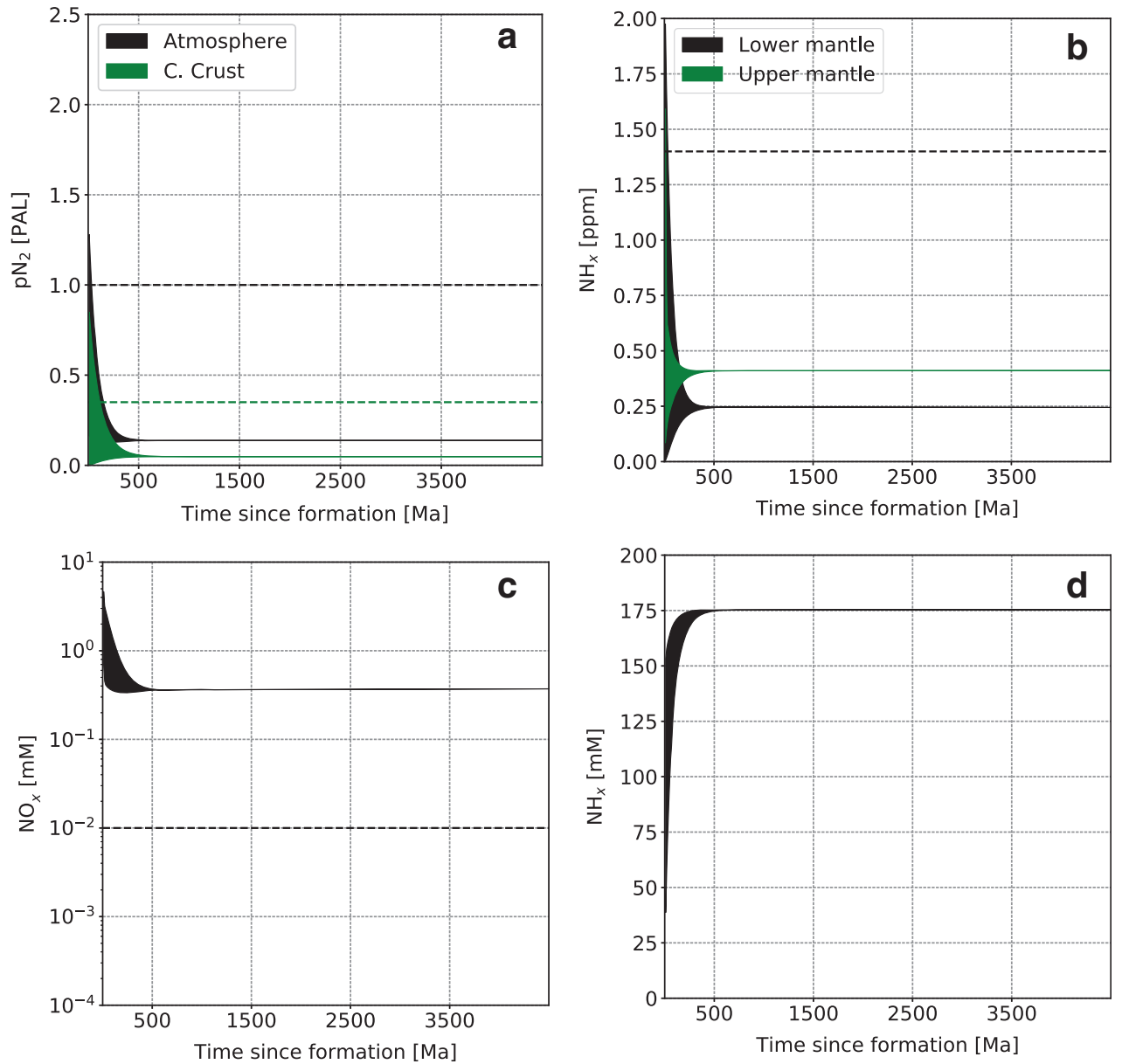

FIG. B3. Nitrogen content as a function of time in the main model reservoirs. (a) Atmospheric $\mathrm{N}_{2}$, (b) lower mantle $\left(\mathrm{NH}_{x}\right)$, oceanic $\mathrm{NO}_{x}(\mathbf{c})$ and $\mathrm{NH}_{x}(\mathbf{d})$. Dashed lines represent present-day values. For upper mantle and oceanic $\mathrm{NH}_{x}$, these values are $3.5 \mathrm{ppm}$ and $3 \times 10^{-4} \mathrm{~m} M$, respectively, and therefore do not appear on the figures. 

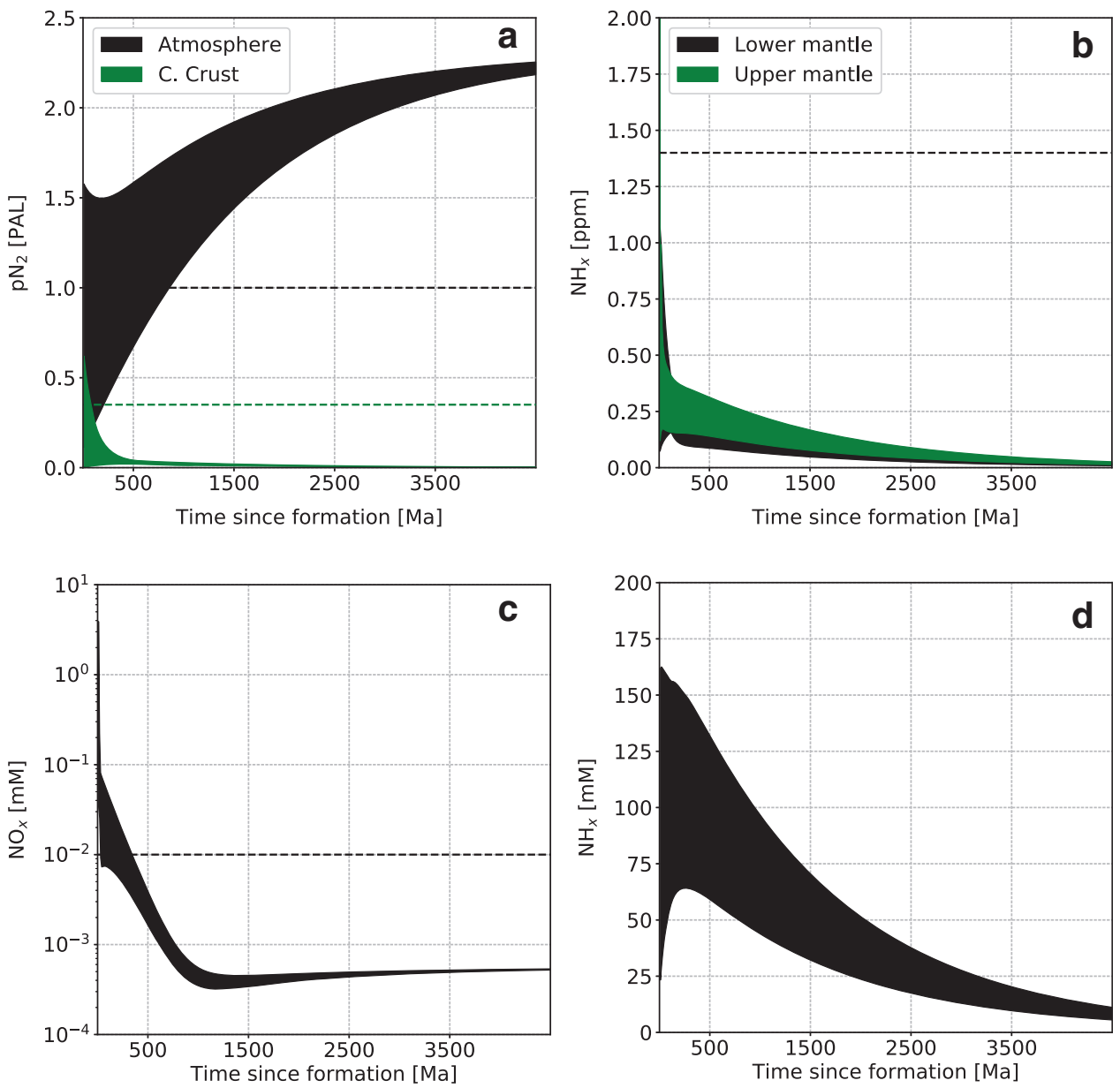

FIG. B4. Nitrogen content as a function of time in the main model reservoirs. (a) Atmospheric $\mathrm{N}_{2}$, (b) lower mantle $\left(\mathrm{NH}_{x}\right)$, oceanic $\mathrm{NO}_{x}(\mathbf{c})$ and $\mathrm{NH}_{x}(\mathbf{d})$. Dashed lines represent present-day values. For upper mantle and oceanic $\mathrm{NH}_{x}$, these values are $3.5 \mathrm{ppm}$ and $3 \times 10^{-4} \mathrm{~m} M$, respectively, and therefore do not appear on the figures.

volume allows more nitrogen to be dissolved and thus results in a lower atmospheric $\mathrm{pN}_{2}$. This leads to more nitrogen being cycled through hydrothermal vents and, thus, a higher $\mathrm{NH}_{x}$ content. In contrast, as no additional source of $\mathrm{NO}_{x}$ is added, its concentration is slightly reduced. The influence on the lower mantle is also minimal.

\section{Appendix B.3. Evolution with a small nitrogen budget}

As discussed in the work of Johnson and Goldblatt (2015), the bulk silicate Earth nitrogen budget is uncertain, and the $3.4 \times 10^{19} \mathrm{~kg} \mathrm{~N}$ value that we used is a high-end estimate. Here we present typical evolution curves for a global budget of $9.3 \times 10^{18} \mathrm{~kg} \mathrm{~N}$. Figure B3 is for a high abiotic atmospheric fixation rate and corresponds to Fig. 3. Figure B4 is for a low abiotic atmospheric fixation rate and corresponds to Fig. 4. The qualitative behavior is very close to the case with the larger bulk silicate nitrogen budget, but with all reservoirs being reduced by a similar ratio.

\section{Acknowledgments}

This project was supported by the ELSI Origins Network (EON), which is supported by a grant from the John Templeton
Foundation. The opinions expressed in this publication are those of the author(s) and do not necessarily reflect the views of the John Templeton Foundation. This work was also supported by a JSPS KAKENHI Grant-in-Aid for Scientific Research on Innovative Areas "Hadean Bioscience." We would like to thank B. Johnson, D. Papineau, and an anonymous reviewer for the thoughtful comments. M.L. would also like to thank D. Höning and H. Kurokawa for fruitful discussions.

\section{References}

Airapetian, V., Glocer, A., Gronoff, G., Hébrard, E., and Danchi, W. (2016) Prebiotic chemistry and atmospheric warming of early Earth by an active young Sun. Nat Geosci 9:452-455.

Arculus, R. and Delano, J.W. (1980) Implications for the primitive atmosphere of the oxidation state of the Earth's upper mantle. Nature 288:72-74.

Barron, E.J., Hay, W.W., and Thompson, S. (1989) The hydrologic cycle: a major variable during Earth history. $\mathrm{Pa}$ laeogeogr Palaeoclimatol Palaeoecol 75:157-174.

Belousova, E., Kostitsyn, Y., Griffin, W.L., Begg, G.C., O'Reilly, S.Y., and Pearson, N.J. (2010) The growth of the continental crust: constraints from zircon Hf-isotope data. Lithos 119:457-466. 
Bland, W. and Rolls, D. (1998) Weathering: An Introduction to the Scientific Principles, Arnold, London.

Bogard, D.D., Clayton, R.N., Marti, K., Owen, T., and Turner, G. (2001) Martian volatiles: isotopic composition, origin, and evolution. Space Sci Rev 96:425-458.

Borucki, W.J. and Chameides, W.L. (1984) Lightning: estimates of the rates of energy dissipation and nitrogen fixation. Rev Geophys 22:363-372.

Boudou, J.-P., Schimmelmann, A., Ader, M., Mastalerz, M., Sebilo, M., and Gengembre, L. (2008) Organic nitrogen chemistry during low-grade metamorphism. Geochim Cosmochim Acta 72:1199-1221.

Brandes, J., Boctor, N., Cody, G., Cooper, B., Hazen, R.M., and Yoder, H.S. (1998) Abiotic nitrogen reduction on the early Earth. Nature 395:365-368.

Busigny, V., Cartigny, P., Philippot, P., Ader, M., and Javoy, M. (2003) Massive recycling of nitrogen and other fluidmobile elements $(\mathrm{K}, \mathrm{Rb}, \mathrm{Cs}, \mathrm{H})$ in a cold slab environment: evidence from HP to UHP oceanic metasediments of the Schistes Lustrés Nappe (Western Alps, Europe). Earth Planet Sci Lett 215:27-42.

Campbell, I.H. and O'Neill, H.S.C. (2012) Evidence against a chondritic Earth. Nature 483:553-558.

Canil, D. (1997) Vanadium partitioning and the oxidation state of Archaean komatiite magmas. Nature 389:23-26.

Capone, D.G., Popa, R., Flood, B., and Nealson, K.H. (2006) Geochemistry. Follow the nitrogen. Science 312: 708-709.

Chameides, W. (1975) Tropospheric odd nitrogen and the atmospheric water vapor cycle. J Geophys Res 80:49894996.

Chyba, C. and Sagan, C. (1992) Endogenous production, exogenous delivery and impact-shock synthesis of organic molecules: an inventory for the origins of life. Nature 355:125-132.

Cleaves, H.J., Chalmers, J.H., Lazcano, A., Miller, S.L., and Bada, J.L. (2008) A reassessment of prebiotic organic synthesis in neutral planetary atmospheres. Orig Life Evol Biosph 38:105-115.

Coffin, M.F., Pringle, M.S., Duncan, R.A., Gladczenko, T.P., Storey, M., Müller, R.D., and Gahagan, L.A. (2002) Kerguelen hotspot magma output since $130 \mathrm{Ma}$. Journal of Petrology 43:1121-1137.

Delano, J.W. (2001) Redox history of the Earth's interior since 3900 Ma: implications for prebiotic molecules. Orig Life Evol Biosph 31:311-341.

Dhuime, B., Hawkesworth, C.J., Cawood, P.A., and Storey, C.A. (2012) A change in the geodynamics of continental growth 3 billion years ago. Science 335:1334-1336.

Dodd, M.S., Papineau, D., Grenne, T., Slack, J.F., Rittner, M., Pirajno, F., O'Neil, J., and Little, C.T. (2017) Evidence for early life in Earth's oldest hydrothermal vent precipitates. Nature 543:60-64.

Ferrachat, S. and Ricard, Y. (1998) Regular vs. chaotic mantle mixing. Earth Planet Sci Lett 155:75-86.

Folsome, C., Brittain, A., Smith, A., and Chang, S. (1981) Hydrazines and carbohydrazides produced from oxidized carbon in Earth's primitive environment. Nature 294: 64-65.

Frost, D.J. and McCammon, C.A. (2008) The redox state of Earth's mantle. Annu Rev Earth Planet Sci 36:389-420.

Galloway, J.N., Leach, A.M., Bleeker, A., and Erisman, J.W. (2013) A chronology of human understanding of the nitrogen cycle. Philos Trans R Soc Lond B Biol Sci 368, doi:10.1098/ rstb.2013.0120.
Goldblatt, C., Claire, M.W., Lenton, T.M., Matthews, A.J., Watson, A.J., and Zahnle, K.J. (2009) Nitrogen-enhanced greenhouse warming on early Earth. Nat Geosci 2:891-896.

Harrison, C.G.A. (1999) Constraints on ocean volume change since the Archean. Geophys Res Lett 26:1913-1916.

Hay, W.W, Sloan, J.L., II, and Wold, C.N. (1988) Mass/age distribution and composition of sediments on the ocean floor and the global rate of sediment subduction. J Geophys Res: Solid Earth 93:14933-14940.

Hayden, L.A. and Watson, E.B. (2007) A diffusion mechanism for core-mantle interaction. Nature 450:709-711.

Heinrich, M.N., Khare, B.N., and McKay, C.P. (2007) Prebiotic organic synthesis in early Earth and Mars atmospheres: laboratory experiments with quantitative determination of products formed in cold plasma flow reactor. Icarus 191:765-778.

Holland, H.D. (1984) The Chemical Evolution of the Atmosphere and Oceans, Princeton University Press, Princeton, NJ.

Huene, R. and Scholl, D.W. (1991) Observations at convergent margins concerning sediment subduction, subduction erosion, and the growth of continental crust. Rev Geophysics 29:279-316.

Hutchins, K.S. and Jakosky, B.M. (1996) Evolution of martian atmospheric argon: implications for sources of volatiles. J Geophys Res: Planets 101:14933-14949.

Javoy, M., Kaminski, E., Guyot, F., Andrault, D., Sanloup, C., Moreira, M., Labrosse, S., Jambon, A., Agrinier, P., Davaille, A., and Jaupart, C. (2010) The chemical composition of the Earth: enstatite chondrite models. Earth Planet Sci Lett 293: 259-268.

Johnson, B. and Goldblatt, C. (2015) The nitrogen budget of Earth. Earth-Science Reviews 148:150-173.

Kasting, J.F., Eggler, D.H., and Raeburn, S.P. (1993) Mantle redox evolution and the oxidation state of the Archean atmosphere. J Geol 101:245-257.

Korenaga, J. (2008) Plate tectonics, flood basalts and the evolution of Earth's oceans. Terra Nova 20:419-439.

Kounaves, S.P., Carrier, B.L., O’Neil, G.D., Stroble, S.T., and Claire, M.W. (2014) Evidence of martian perchlorate, chlorate, and nitrate in Mars meteorite EETA79001: implications for oxidants and organics. Icarus 229:206-213.

Lammer, H., Lichtenegger, H., Khodachenko, M., Kulikov, Y.N., and Griessmeier, J. (2011) The loss of nitrogen-rich atmospheres from Earth-like exoplanets within M-star habitable zones. In Molecules in the Atmospheres of Extrasolar Planets, Vol. 450, edited by J.P. Beaulieu, S. Dieteres, and G. Tinetti, Astronomical Society of the Pacific, San Francisco, p 139.

Li, Y. and Keppler, H. (2014) Nitrogen speciation in mantle and crustal fluids. Geochim Cosmochim Acta 129:13-32.

Li, Y., Huang, R., Wiedenbeck, M., and Keppler, H. (2015) Nitrogen distribution between aqueous fluids and silicate melts. Earth Planet Sci Lett 411:218-228.

Mackin, J.E. and Aller, R.C. (1984) Ammonium adsorption in marine sediments. Limnol Oceanogr 29:250-257.

Mahaffy, P.R., Webster, C.R., Atreya, S.K., Franz, H., Wong, M., Conrad, P.G., Harpold, D., Jones, J.J., Leshin, L.A., Manning, H., Owen, T., Pepin, R.O., Squyres, S., Trainer, M., and the MSL Team. (2013) Abundance and isotopic composition of gases in the martian atmosphere from the Curiosity rover. Science 341:263-266.

Mancinelli, R.L. and McKay, C.P. (1988) The evolution of nitrogen cycling. Orig Life Evol Biosph 18:311-325.

Marty, B. (1995) Nitrogen content of the mantle inferred from $\mathrm{N}_{2} /$ Ar correlation in oceanic basalts. Nature 377:326-329. 
Marty, B., Zimmermann, L., Pujol, M., Burgess, R., and Philippot, P. (2013) Nitrogen isotopic composition and density of the Archean atmosphere. Science 342:101-104.

Marty, B., Avice, G., Sano, Y., Altwegg, K., Balsiger, H., Hässig, M., Morbidelli, A., Mousis, O., and Rubin, M. (2016) Origins of volatile elements $(\mathrm{H}, \mathrm{C}, \mathrm{N}$, noble gases) on Earth and Mars in light of recent results from the ROSETTA cometary mission. Earth Planet Sci Lett 441:91-102.

McDonough, W.F. and Sun, S.-S. (1995) The composition of the Earth. Chem Geol 120:223-253.

McElroy, M.B., Kong, T.Y., and Yung, Y.L. (1977) Photochemistry and evolution of Mars' atmosphere: a Viking perspective. J Geophys Res 82:4379-4388.

McLennan, S.M. and Taylor, S. (1983) Continental freeboard, sedimentation rates and growth of continental crust. Nature 306:169-172.

Mikhail, S. and Sverjensky, D.A. (2014) Nitrogen speciation in upper mantle fluids and the origin of Earth's nitrogen-rich atmosphere. Nat Geosci 7:816-819.

Minobe, S., Nakajima, Y., Hirose, K., and Ohishi, Y. (2015) Stability and compressibility of a new iron-nitride $\beta-\mathrm{Fe}_{7} \mathrm{~N}_{3}$ to core pressures. Geophys Res Lett 42:5206-5211.

Miyakawa, S., Cleaves, H.J., and Miller, S.L. (2002) The cold origin of life: A. Implications based on the hydrolytic stabilities of hydrogen cyanide and formamide. Orig Life Evol Biosph 32:195-208.

Mohapatra, R.K. and Murty, S.V.S. (2003) Precursors of Mars: constraints from nitrogen and oxygen isotopic compositions of martian meteorites. Meteorit Planet Sci 38:225-241.

Mojzsis, S.J., Arrhenius, G., McKeegan, K., Harrison, T., Nutman, A., and Friend, C. (1996) Evidence for life on Earth before 3,800 million years ago. Nature 384:55-59.

Müller, R.D., Sdrolias, M., Gaina, C., and Roest, W.R. (2008) Age, spreading rates, and spreading asymmetry of the world's ocean crust. Geochem Geophys Geosyst 9, doi:10.1029/ 2007 GC001743.

Mumma, M.J. and Charnley, S.B. (2011) The chemical composition of comets-emerging taxonomies and natal heritage. Annu Rev Astron Astrophys 49:471-524.

Navarro-Gonzalez, R., McKay, C.P., and Mvondo, D.N. (2001) A possible nitrogen crisis for Archaean life due to reduced nitrogen fixation by lightning. Nature 412:61-64.

Nguyen, D.A., Iwaniw, M.A., and Fogler, H.S. (2003) Kinetics and mechanism of the reaction between ammonium and nitrite ions: experimental and theoretical studies. Chem Eng Sci 58:4351-4362.

Noffke, N., Christian, D., Wacey, D., and Hazen, R.M. (2013) Microbially induced sedimentary structures recording an ancient ecosystem in the $c a$. 3.48 billion-year-old Dresser Formation, Pilbara, Western Australia. Astrobiology 13:1103-1124.

Papineau, D., Mojzsis, S., Karhu, J., and Marty, B. (2005) Nitrogen isotopic composition of ammoniated phyllosilicates: case studies from Precambrian metamorphosed sedimentary rocks. Chem Geol 216:37-58.

Pope, E.C., Bird, D.K., and Rosing, M.T. (2012) Isotope composition and volume of Earth's early oceans. Proc Natl Acad Sci USA 109:4371-4376.

Sander, R. (2015) Compilation of Henry's law constants (Version 4.0) for water as solvent. Atmos Chem Phys 15:4399-4981.

Sano, Y., Takahata, N., Nishio, Y., Fischer, T.P., and Williams, S.N. (2001) Volcanic flux of nitrogen from the Earth. Chem Geol 171:263-271.

Schwartz, A.W. (1981) Chemical evolution-the genesis of the first organic compounds. In Marine Organic Chemistry
Evolution, Composition, Interactions and Chemistry of Organic Matter in Seawater, Volume 31 of Elsevier Oceanography Series, edited by E.K. Duursma and R. Dawson, Elsevier, Amsterdam, pp 7-30.

Schwieterman, E.W., Robinson, T.D., Meadows, V.S., Misra, A., and Domagal-Goldman, S. (2015) Detecting and constraining $\mathrm{N}_{2}$ abundances in planetary atmospheres using collisional pairs. Astrophys J 810, doi:10.1088/0004-637X/ 810/1/57.

Shizgal, B.D. and Arkos, G.G. (1996) Nonthermal escape of the atmospheres of Venus, Earth, and Mars. Rev Geophys 34:483505.

Smith, S. (1984) Phosphorus versus nitrogen limitation in the marine environment. Limnol Oceanogr 29:1149-1160.

Som, S.M., Buick, R., Hagadorn, J.W., Blake, T.S., Perreault, J.M., Harnmeijer, J.P., and Catling, D.C. (2016) Earth's air pressure 2.7 billion years ago constrained to less than half of modern levels. Nat Geosci 9:1-5.

Stern, J.C., Sutter, B., Freissinet, C., Navarro-Gonzlez, R., McKay, C.P., Archer, P.D., Buch, A., Brunner, A.E., Coll, P., Eigenbrode, J.L., Fairen, A.G., Franz, H.B., Glavin, D.P., Kashyap, S., McAdam, A.C., Ming, D.W., Steele, A., Szopa, C., Wray, J.J., Martin-Torres, F.J., Zorzano, M.-P., Conrad, P.G., Mahaffy, P.R., and the MSL Science Team. (2015) Evidence for indigenous nitrogen in sedimentary and aeolian deposits from the Curiosity rover investigations at Gale Crater, Mars. Proc Natl Acad Sci USA 112:42454250 .

Stüeken, E.E., Buick, R., Guy, B.M., and Koehler, M.C. (2015) Isotopic evidence for biological nitrogen fixation by molybdenum-nitrogenase from 3.2 Gyr. Nature 105:13021312 .

Stüeken, E.E., Kipp, M.A., Koehler, M.C., Schwieterman, E.W., Johnson, B., and Buick, R. (2016) Modeling $\mathrm{pN}_{2}$ through geological time: implications for planetary climates and atmospheric biosignatures. Astrobiology 16: 949-963.

Summers, D.P. (2005) Ammonia formation by the reduction of nitrite/nitrate by FeS: ammonia formation under acidic conditions. Orig Life Evol Biosph 35:299-312.

Thomazo, C. and Papineau, D. (2013) Biogeochemical cycling of nitrogen on the early Earth. Elements 9:345-351.

Trail, D., Watson, E.B., and Tailby, N.D. (2011) The oxidation state of Hadean magmas and implications for early Earth's atmosphere. Nature 480:79-82.

Turcotte, D. (1980) On the thermal evolution of the Earth. Earth Planet Sci Lett 48:53-58.

Van Keken, P. and Zhong, S. (1999) Mixing in a 3D spherical model of present-day mantle convection. Earth Planet Sci Lett 171:533-547.

Veizer, J. (1973) Sedimentation in geologic history: recycling vs. evolution or recycling with evolution. Contrib Mineral Petrol 38:261-278.

Vitousek, P.M. and Howarth, R.W. (1991) Nitrogen limitation on land and in the sea: how can it occur? Biogeochemistry 13: 87-115.

Von Blanckenburg, F. (2005) The control mechanisms of erosion and weathering at basin scale from cosmogenic nuclides in river sediment. Earth Planet Sci Lett 237:462479.

Wilde, S.A., Valley, J.W., Peck, W.H., and Graham, C.M. (2001) Evidence from detrital zircons for the existence of continental crust and oceans on the Earth 4.4 Gyr ago. Nature 409:175-178. 
Wolff, E.W. (1995) Nitrate in polar ice. In Ice Core Studies of Global Biogeochemical Cycles, edited by R.J. Delmas, Springer, Berlin, pp 195-224.

Wordsworth, R. (2016) Atmospheric nitrogen evolution on Earth and Venus. Earth Planet Sci Lett 447:103-111.

Yung, Y. and McElroy, M. (1979) Fixation of nitrogen in the prebiotic atmosphere. Science 203:1002-1004.

Zahnle, K.J. (1986) Photochemistry of methane and the formation of hydrocyanic acid (HCN) in the Earth's early atmosphere. J Geophys Res: Atmospheres 91:28192834.

Zhang, Y. and Zindler, A. (1993) Distribution and evolution of carbon and nitrogen in Earth. Earth Planet Sci Lett 117:331345.

Zhu-Barker, X., Cavazos, A.R., Ostrom, N.E., Horwath, W.R., and Glass, J.B. (2015) The importance of abiotic reactions for nitrous oxide production. Biogeochemistry 126:251-267.
Address correspondence to: Matthieu Laneuville

Earth-Life Science Institute

Tokyo Institute of Technology

2-12-IE-1 Ookayama

Meguro-ku

Tokyo 152-8551

Japan

E-mail: mlaneuville@elsi.jp

Submitted 7 June 2017

Accepted 31 December 2017

Associate Editor: Christopher McKay

\begin{tabular}{|c|} 
Abbreviations Used \\
$\mathrm{MORB}=$ mid-ocean ridge basalt \\
$\mathrm{PAL}=$ present atmospheric levels
\end{tabular}

